Discussion Paper Series N 2013-16

Equity Portfolio Diversification: How Many Stocks are Enough? Evidence from Five Developed Markets

Vitali ALEXEEV

University of Tasmania

Francis TAPON University of Guelph

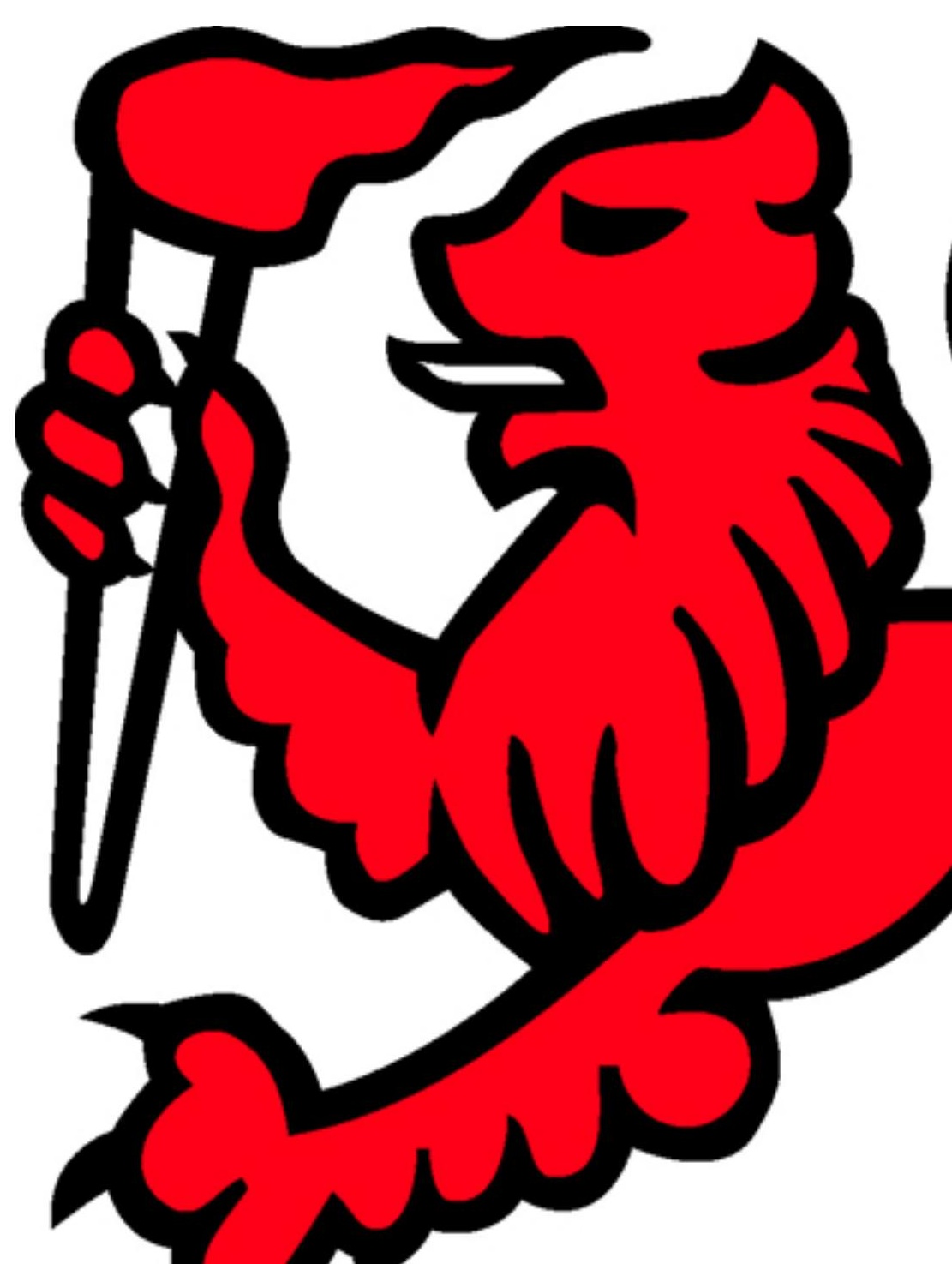




\title{
Equity portfolio diversification: how many stocks are enough? Evidence from five developed markets.
}

\author{
Vitali Alexeev ${ }^{\mathrm{a}, *}$, Francis Tapon ${ }^{\mathrm{b}}$ \\ ${ }^{a}$ School of Economics and Finance, University of Tasmania, Hobart, Australia 7001, Tel: +61 (3) 6226 \\ 2335 \\ ${ }^{b}$ Department of Economics, University of Guelph, Ontario, Canada N1G 2W1, Tel: +1 (519) 824 4120 \\ (ext. 52657)
}

\begin{abstract}
In this study of five developed markets we analyse the sizes of portfolios required for achieving most diversification benefits. Using daily data, we trace the year-to-year dynamic of these sizes between 1975 and 2011. We compute several widely-accepted measures of risk and use an extreme risk measure to account for black swan events. In addition to providing portfolio size recommendations for an average investor, we estimate confidence bands around central measures of risk and offer recommendations for attaining most diversification benefits 90 percent of the time instead of on average. We find that investors concerned with extreme risk can achieve diversification benefits with a relatively small number of stocks.

Keywords: Portfolio diversification, international investing, heavy tailed risk, expected shortfall, time series standard deviation, terminal wealth standard deviation.

JEL classification: G11, G15, C63

\footnotetext{
${ }^{*}$ Corresponding author

Email addresses: valexeev@utas.edu.au (Vitali Alexeev), ftapon@uoguelph.ca (Francis Tapon)
} 


\section{Introduction}

In this paper, we present new answers to a decades old question ${ }^{1}$ about the number of stocks $^{2}$ required to reduce the level of diversifiable risk in equity portfolios. Using daily data $^{3}$ for five developed financial markets (the US, the UK, Japan, Canada and Australia) ${ }^{4}$, we trace the year-to-year dynamic of required portfolio sizes between 1975 and 2011. We calculate several widely-accepted measures of risk: standard deviation, expected shortfall at $1 \%$, and terminal wealth standard deviation. This is the first empirical study to use an extreme risk measure to account for black swan events related to the recent Global Financial Crisis, as well as the more common asymmetries in returns during bull and bear markets. To the best of our knowledge, the extant literature only provides portfolio size recommendations for an average investor. Thus, in addition to providing portfolio size recommendations for an average investor, we estimate confidence bands around two central measures of risk to provide portfolio size recommendations for attaining most diversification benefits 90 percent of the time instead of on average. Differences in market conditions across periods, in different countries, and with different risk measures make a comparative analysis of the benefits of diversification fraught with difficulties. Consequently, we define a diversification measure that is exclusively focused on diversifiable risk and is bounded between 0 and 1 . We find

\footnotetext{
${ }^{1}$ The question of the optimal number of stocks in a diversified portfolio has been extensively studied in the literature, especially for the US. Using a variety of risk measures, authors have not yet reached a definitive conclusion. The pioneering paper by Evans and Archer (1968) was the first study to evaluate the reduction in portfolio risk as portfolio size increased. With standard deviation as a risk measure, they show that on average eight to ten stocks are sufficient to achieve most of the benefits of diversification. Standard deviation was commonly used as a measure of risk in earlier studies (see for example Fisher and Lorie, 1970; Wagner and Lau, 1971; Solnik, 1974; Bloomfield et al., 1977; Bird and Tippett, 1986; Statman, 1987) and continued to be a popular choice in the past decade (e.g., Brands and Gallagher, 2005; Benjelloun, 2010). Several other measures include variance (Johnson and Shannon, 1974; Elton and Gruber, 1977; Beck et al., 1996), mean absolute deviation (Fisher and Lorie, 1970; Fielitz, 1974), and terminal wealth standard deviation (O'Neal, 1997; Brands and Gallagher, 2005; Benjelloun, 2010). Within the linear market model framework, measures of portfolio beta, $R^{2}$, residual variance have been used in assessing level of diversification (see for example Wagner and Lau, 1971; Klemkosky and Martin, 1975). Correlation between returns on a portfolio and the market index was also used in Beck et al. (1996); Dbouk and Kryzanowski (2009); Kryzanowski and Singh (2010). In addition to the measures mentioned above, Fisher and Lorie (1970)'s study was the only one that used Gini's mean difference and coefficient of concentration as measures of portfolio diversification. Several examples of downside measures of risk have also been found in the literature: semi-variance (O'Neal, 1997; Kryzanowski and Singh, 2010) and mean shortfall (O'Neal, 1997). Although Hyung and de Vries (2005) and Ibragimov and Walden (2007) provide some theoretical justification for the use of extremely heavy-tailed risks in measuring portfolio diversification, the empirical analyses are only starting to emerge (e.g., Hyung and de Vries, 2012).

${ }^{2}$ Hereafter, referred to as portfolio size.

${ }^{3}$ Most papers use lower frequencies varying from weekly (Solnik, 1974); monthly (Klemkosky and Martin, 1975; Beck et al., 1996; Benjelloun, 2010; Kryzanowski and Singh, 2010); quarterly (Johnson and Shannon, 1974; O'Neal, 1997); semi-annual (Evans and Archer, 1968) to annual data (Fisher and Lorie, 1970; Jennings, 1971).

${ }^{4}$ Most of the studies on diversification and portfolio size focus on the US markets and relatively few study other markets. The exceptions are Solnik (1974) who, analyses the US and markets in the UK, Germany, France, Switzerland, Italy, Belgium and the Netherlands; Bird and Tippett (1986) and Brands and Gallagher (2005) report on Australia; Copp and Cleary (1999) and Kryzanowski and Singh (2010) study Canada; Byrne and Lee (2000) study the UK.
} 
that the correlation structures in the five markets change during periods of financial market distress. We also find that these changes differ in periods of market-wide crises and industryspecific meltdowns, that have important implications for recommended portfolio sizes.

Although it is commonly recommended that risk-averse investors hold a number of uncorrelated securities in their portfolios to achieve some degree of diversification, it is not readily obvious how many stocks are required to avoid most diversifiable risk. Holding too few stocks exposes the investor to unnecessary idiosyncratic risk. Holding too many stocks is costly both in terms of the cost of numerous transactions needed to build the initial portfolio and the opportunity cost of monitoring a large diversified portfolio. The larger the number of stocks in a portfolio, the higher the chances of underperforming the benchmark after fees. If it is possible to eliminate most diversifiable risk with a small portfolio, the need for the large portfolios typically held by equity funds is unjustified. Campbell et al. (2001), however, have shown that firm specific risk in the U.S. has grown over the past thirty years relative to the overall volatility of the stock market and that correlations between stocks have correspondingly decreased, reinforcing the advisability of larger portfolios.

We use a simulation approach to construct random portfolios ${ }^{5}$ based on actual daily equity returns over the period 1975 to 2011 . We construct equally weighted random portfolios of different sizes ranging from portfolios consisting of only one security to a broad market portfolio including all actively traded securities in the market. For each of these portfolios, we analyse several measures of risk both within a sub-period and across different stock markets. We focus on estimates of time series standard deviation (SD), expected shortfall (ES) and terminal wealth standard deviation (TWSD) for portfolios of different sizes. ${ }^{6}$ We use SD as a benchmark to be able to compare our results to the previous literature. The ES provides a coherent downside risk measure essential for accounting for black swan events. The TWSD measure is a standard benchmark for buy-and-hold no-rebalancing portfolios. We compare five developed equity markets and trace the dynamics of diversification benefits over the past 37 years in these markets. Note, that we do not attempt to build international portfolios or assess the benefits of international diversification. Put another way, we analyse each of the five markets separately from the perspective of domestic investors. Pooling the five markets together, would contaminate our results with exchange rate risk.

We find that investors concerned with tail risk can achieve diversification benefits with a relatively small number of stocks. For the same level of risk reduction, our results for risk measures that do not consider extreme $\operatorname{losses}^{7}$ find no substantial differences in portfolio sizes

\footnotetext{
${ }^{5}$ Using individual investor data from a large US discount brokerage house, Goetzmann and Kumar (2008) show that, on average, portfolios constructed from randomly selected stocks exhibit lower risk than those of actual investors. The discrepancy is consistent with over-confidence, trend-following behavior, and local bias. Thus, a strategy of randomly selecting stocks eliminates behavioural biases and concentrates solely on the effects of portfolio sizes on their riskiness.

${ }^{6}$ In addition to the risk measures outlined above, we have also estimated other common measures of risk, performance and diversification. We considered lower partial moments (LPMs), Value-at-Risk (VaR), mean absolute deviation (MAD) and median absolute deviation for risk; arithmetic and geometric returns, Sharpe and Treynor measures for performance; $R^{2}$ and correlation coefficients with the market portfolio for diversification. Due to article length restrictions, we provide these additional results on our website (URL site is omitted for double blind review).

${ }^{7}$ See the measures mentioned in footnote 6 .
} 
when compared to results using standard deviation as a risk measure. Previous literature provides answers to the question of portfolio size only for an average investor. To improve on these results we construct $90 \%$ confidence bands around our calculated central risk measures that give us an upper limit to the number of stocks required in a portfolio that assures investors of the desired level of diversification $90 \%$ of the time instead of on average.

We find that portfolios aimed at diversifying extreme losses measured by $E S_{1 \%}$ are, on average, smaller in size (US: 16; UK: 16; Japan: 13; Canada: 19; Australia: 18 stocks), compared to when SD is used as a risk measure (US: 23; UK: 21; Japan: 19; Canada: 25; Australia: 24 stocks). To achieve the same level of risk reduction but with $90 \%$ confidence, instead of on average, we find that portfolios aimed at diversifying extreme losses (e.g., $E S_{1 \%}$ ) are typically larger (US: 52; UK: 44; Japan: 50; Canada: 41; Australia: 38 stocks) than when we use SD as our risk metric (US: 49; UK: 43; Japan: 39; Canada: 40; Australia: 38 stocks). In sum, as we will show, the portfolio sizes needed to diversify idiosyncratic risk away with a given level of confidence depend on: (i) the measure of risk; (ii) the required confidence level needed to achieve a $90 \%$ reduction in diversifiable risk; (iii) market locale; (iv) the changing correlation structure between stock returns during periods of financial distress; and (v) the differences in correlation structures in periods of market-wide crises and industry-specific meltdowns.

Portfolio sizes recommended in this paper are in sharp contrast with mutual fund industry norms as well as the portfolio holdings of individual investors. For example, the number of stocks held by an average, all-domestic US equity fund is 77 stocks. ${ }^{8}$ These large portfolios are supported by some academic studies suggesting that the number of stocks in a portfolio should be in excess of 50 (Copp and Cleary, 1999; Domian et al., 2007; Benjelloun, 2010; Kryzanowski and Singh, 2010). However, the average fund underperforms the market index, frequently needs rebalancing and thus is expensive to manage. In contrast, other studies indicate that substantial diversification benefits can be achieved by owning as few as 6-15 stocks (Evans and Archer, 1968; Jennings, 1971; Fielitz, 1974; Johnson and Shannon, 1974; Solnik, 1974; Bird and Tippett, 1986; Tang, 2004; Brands and Gallagher, 2005). In fact, Goetzmann and Kumar (2008, p.437) find in the Survey of Consumer Finances of 62,387 US households that the average American investor owns 4 stocks (with a median of 3). Ivkovic et al. (2008, p.619, Table 1) discover similar results of 4 to 11 stocks depending on the wealth of investors.

Many of the conclusions in the studies cited in footnote 1 are based on either the mean or the median measure of risk among a large number of randomly selected $n$-stock portfolios. However, as noted in Tang (2004, pp.155-156) these "...findings are based on the expected portfolio variances (or risk) for different portfolio sizes, which are different from the actual portfolio risk. There is no guarantee that the risk of one particular portfolio is the same as the expected risk with the same portfolio size (i.e., risk of the portfolio risk exists). Hence, there are additional sample risks in that your portfolio may not be the same as the population average." Evans and Archer (1968) were the first to calculate the 95\% confidence limit to

\footnotetext{
${ }^{8}$ On July 3, 2013, the interquartile range for the number of holdings of 2,088 all domestic US equity mutual funds registered in the Morningstar database when index funds are excluded is 49 to 129 stocks. Source: Morningstar Fund Screener.
} 


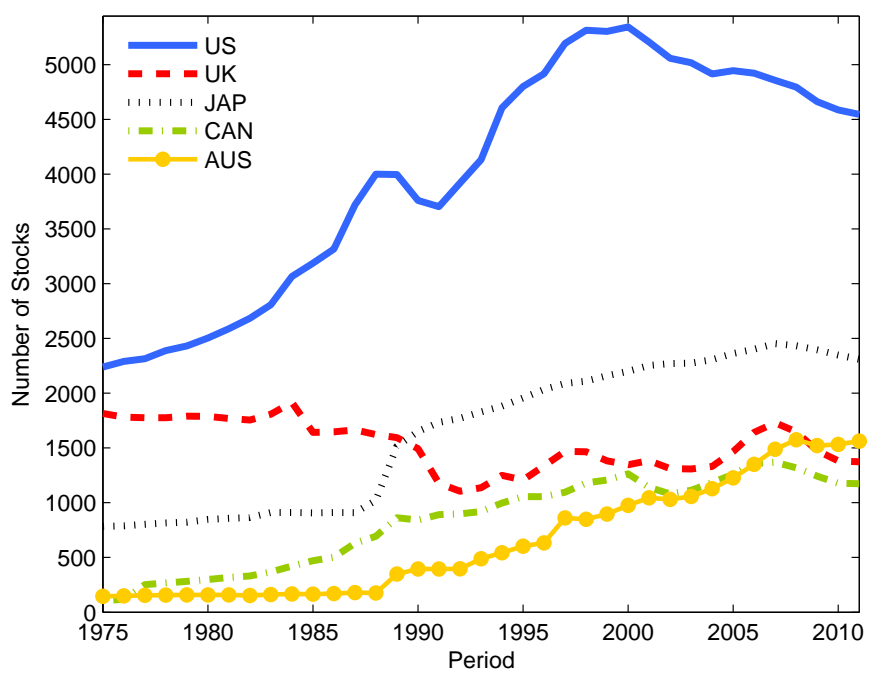

Figure 1: Number of common stocks by country. The lines represent the number of stocks used in our analysis after removing stocks that have traded less than $25 \%$ of the trading days in a particular year. For example, in 2011, the total number of stocks across the five markets used in the analysis is 10,964 (down from 11,456 for which data were available).

their central measure but did not infer the portfolio size recommendations based on this result (Evans and Archer, 1968, Figure 1, p.765). In fact, in the past 45 years (since Evans and Archer, 1968) no research has been done to investigate the relationship of portfolio size and confidence levels that assures, at a specific certainty level, a reduction in risk.

In Section 2, we discuss our data and methodology. In Section 3, we present our results. We draw our conclusions in Section 4.

\section{Data and Methodology}

We assume that (i) each portfolio contains only common stocks; (ii) purchases are financed without borrowing; (iii) investors' actions will not influence the price and/or dividend of an individual stock; (iv) taxes are not considered. These assumptions are similar to those in Jennings (1971). We analyse each of the five markets separately to avoid contaminating our results with exchange rate fluctuations. Our data are obtained from Thomson Reuters Datastream and consist of daily total return observations on common stocks listed on the NYSE-AMEX, the Nasdaq, the London, Tokyo, Toronto and Australian stock exchanges between 1975 to 2011. Figure 1 depicts the total number of stocks for each country. To avoid survivorship bias we acquire total return indices for both active and delisted securities. For each of these years, we consider only securities which have traded at least $75 \%$ of the trading days in a particular year. ${ }^{9}$ We do not analyse continental European financial

\footnotetext{
${ }^{9}$ We acknowledge that there may be a small look-ahead bias due to the fact that we eliminate stocks that were delisted during a year. Our data filters do not distinguish between the following subsets of stocks: i) stocks that are listed on the exchange during a particular year but excluded because they are thinly traded (less than $25 \%$ of trading days in a year); ii) stocks that were active but were delisted early in the year (e.g.,
} 
markets since our sampling period includes these countries' transition to a single currency and the subsequent increase in cross-listings of national enterprises in exchanges across the Eurozone.

Portfolio total risk is modeled as a combination of systematic risk and specific or unsystematic risk. As the number of securities included in a portfolio approaches the number of securities in the market, portfolio risk approaches the overall level of systematic risk, that is, market risk, suggesting a relationship that behaves as a decreasing asymptotic function. Reduction in portfolio risk can then be achieved up to the point where all unsystematic risk has been eliminated or where the incremental decrease in unsystematic risk brings insignificant benefits. $^{10}$

We construct portfolios by randomly drawing $n$ stocks without replacement from the entire sample for a particular stock market. These are equally weighted to give a portfolio return $R_{i}^{n}$, where $n=1 . . N$ indicates the number of stocks in the portfolio and $N$ is the total number of actively traded stocks in the subperiod analysed, and $i=1 . . M$ represents the draw number. Given that our sample includes non-surviving stocks, a stock in the chosen portfolio that does not survive in one period, is replaced in the subsequent period with a new randomly selected stock not already in the portfolio.

We construct $M=10,000 n$-stock portfolios for each $n=1 . . N$, unless the number of combinations of $n$ stocks out of $N$ available is lower than $M$. For example, when $n=1$, the number of unique single security portfolios equals $N$ and when $n=N$ only one equally weighted portfolio can be constructed - we define it as the market portfolio. ${ }^{11}$ If $N$ is the total number of stocks available in the market at any given time, the $n$-combination of $N$ stocks is equal to the binomial coefficient $\left(\begin{array}{c}N \\ n\end{array}\right)=\frac{N !}{n !(N-n) !}$. Accounting for all possible combinations is likely to be beyond the capability of even the most modern hardware. We find that 10,000 replications are sufficient to give a robust measure of central tendency of our risk measures.

For each stock $j$ at time $t$ we define returns as

stocks that delisted in March but traded on $90 \%$ of trading days prior to delisting). In fact, including the stocks in the subset (ii) has minimal influence on our overall results. The number of stocks in that subset is very small and the probability of these stocks being chosen in random portfolios of size up to a maximum of 120 stocks out of the total number of stocks available is relatively low.

${ }^{10}$ Several studies (Evans and Archer, 1968; Latane and Young, 1969; Fisher and Lorie, 1970; Wagner and Lau, 1971; Fielitz, 1974; Klemkosky and Martin, 1975; Tole, 1982; Statman, 1987) have conducted statistical tests for evaluating the significance of the incremental change in reduced unsystematic risk. However, these approaches are subject to a replication sensitivity problem related to the number of replications. Increasing the number of replications to construct random portfolios, and thus reducing the estimation error, can lead to conflicting results. For large numbers of replications, these statistical tests may find significant but irrelevant differences in the risk measure. This problem is only partially mitigated in Beck et al. (1996). Consequently, we do not use this approach in this paper.

${ }^{11}$ We prefer equally weighted portfolios to value weighted ones, because when randomly drawing stocks we would like to avoid situations when one stock's weight is disproportionally large (a mega cap stock) relative to other portfolio constituents (all micro cap for the sake of argument). Essentially, that portfolio would be equivalent to a single stock portfolio, where the mega cap stock dominates. Fama makes a similar point in discussing cumulative abnormal returns (see Fama, 1998, p.296, Section 4.2.3. The return metric: value weights versus equal weights). 


$$
r_{j, t}=\log \left(P_{j, t}\right)-\log \left(P_{j, t-1}\right),
$$

where $P_{j, t}$ is the total return index inclusive of dividends. For $n=1 . . N$ the return of the $n$-stock equally weighted random portfolio $i$ at time $t$ is defined as $^{12}$

$$
R_{i, t}^{n} \approx \sum_{j=1}^{n} \frac{\left\{r_{j, t}\right\}_{i}}{n}
$$

and the average time series return over time $t=1$..T of portfolio $i$ can be expressed as

$$
\bar{R}_{i}^{n}=\sum_{t=1}^{T} \frac{R_{i, t}^{n}}{T} .
$$

Let $\Omega_{i}^{n}$ represent a risk measure of an $n$-stock portfolio $i$. We define the average risk metric of $M$ portfolios, each of size $n$, as follows:

$$
\overline{\Omega^{n}}=\sum_{i=1}^{M} \frac{\Omega_{i}^{n}}{M} .
$$

Most studies define the location of a sample center as in (4) above. A few studies use median as a central tendency for the risk metric. Our preference is for the former.

When equally weighted, the market portfolio consisting of all available securities is a unique portfolio, and $\overline{\Omega^{N}}=\Omega^{N}$. If $\overline{\Omega^{1}}$ and $\Omega^{N}$ are risk metrics for the average single-stock and market portfolios, we can define several measures of diversification, $\eta(n)$, for an $n$-stock portfolio. The first measure is an unscaled and unstandardised risk measure. It is simply defined as the average risk metric, $\eta_{1}(n)=\overline{\Omega^{n}}$, and is consistent with those in Evans and Archer (1968); Fielitz (1974); Johnson and Shannon (1974); Beck et al. (1996); Brands and Gallagher (2005). Using this measure of diversification, as $n \rightarrow N$, the asymptote approaches market risk, $\Omega^{N}$ (see Figure 2 panel A).

The second measure, showing only idiosyncratic risk, is consistent with definitions in Klemkosky and Martin (1975) and Kryzanowski and Singh (2010). It is adjusted for market risk and can be represented, in general form, as $\eta_{2}(n)=\overline{\Omega^{n}}-\Omega^{N}$. In this case the asymptote approaches 0 as the number of stocks in the portfolio increases.

The third measure is standardized by $\overline{\Omega^{1}}$ and is consistent with those in Solnik (1974); O'Neal (1997); Tang (2004). It can be expressed as $\eta_{3}(n)=\overline{\Omega^{n}} / \overline{\Omega^{1}}$. The asymptote in this case represents the percentage of the average security risk that cannot be diversified away.

The following standardization, $\eta_{4}(n)=\overline{\Omega^{n}} / \Omega^{N}$, is also useful. In this case, when $n=1$, the measure shows how many times the average security risk is higher than market risk. As

\footnotetext{
${ }^{12}$ We use log returns rather than simple returns because, expressed as simple returns, a $10 \%$ loss in stock value and a subsequent $10 \%$ gain does not leave the investor with the same wealth. Log returns provide symmetric interpretation of gains and losses alleviating the skewness symptom. We recognize that aggregating log returns cross-sectionally is not the same as the log of aggregated simple returns, however, the difference is small when returns are measured over short intervals of time, and are therefore close to zero (see Campbell et al., 1997), as in the case with daily returns employed in this study, and does not qualitatively affect our relative measure of diversification presented below in equation 5 .
} 
Figure 2: Risk as a function of portfolio size.
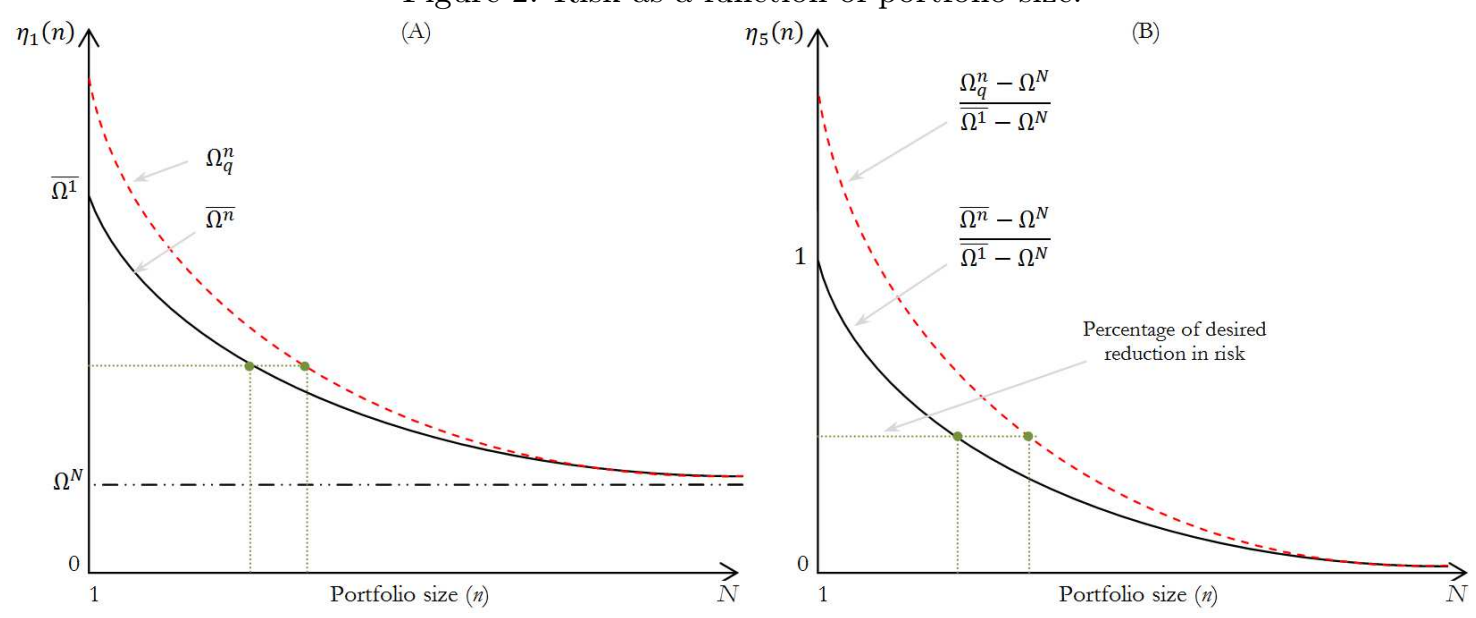

the number of stocks in the portfolio increases, the measure approaches 1 from above. We are unaware of any studies using this representation but include it here for completeness.

Since we are using different measures of risk across different subperiods and countries, and to aid in our comparison, we require a normalised measure that adjusts for both the average security risk and for the level of market risk. To obtain the required number of securities for portfolios with a given level of diversifiable risk, we define a measure exclusively focused on diversifiable risk that is bounded between 0 and 1 as follows:

$$
\eta_{5}(n)=\frac{\overline{\Omega^{n}}-\Omega^{N}}{\overline{\Omega^{1}}-\Omega^{N}} .
$$

The graph in Figure 2 panel (B) illustrates this measure with a solid curve.

In addition, for a series of random draws of $n$-stock portfolios, let $\Omega_{q}^{n}$ be a $q$ th percentile of a risk measure $\Omega^{n}$. Similar to (5) we define:

$$
\eta_{5}(n, q)=\frac{\Omega_{q}^{n}-\Omega^{N}}{\overline{\Omega^{1}}-\Omega^{N}} .
$$

We depict (6) in Figure 2 panel (B) with a dashed curve. The advantage of the risk measures in (5) and (6) is that they can be used to compare diversification benefits across time periods and against other risk measures.

When the market model holds and the variance of portfolio returns is used as the risk measure, equation (5) is the level of idiosyncratic risk of an $n$-stock portfolio relative to the average level of idiosyncratic risk of a single security.

Because, in the finance literature, measuring risk is more contentious than measuring return, we consider several types of risk measures. Our first measure is time series standard deviation (SD), a well accepted measurement of risk of a financial asset or portfolio. This measure allows us to compare our results with those in previous studies. Other important risk measures are downside (or tail) risk measures. Downside risk measures account for deviations below a certain threshold, unlike standard deviation, where positive and negative deviations from the expected level are penalized equally. One advantage of downside risk measures is that they account, to some extent, for the asymmetries in returns during bull and 
bear markets. For this purpose, we use the expected shortfall (ES) measure. An additional conceptually different measure, reported in this study, is terminal wealth standard deviation (TWSD) that assumes no portfolio re-balancing during the period (see Section 2.3 below).

\subsection{Time series standard deviation}

When the risk metric is the standard deviation of a portfolio, we define it as follows: ${ }^{13}$

$$
\Omega_{i}^{n} \equiv \sigma_{i}^{n}=\sqrt{\sum_{t=1}^{T} \frac{\left(R_{i, t}^{n}-\bar{R}_{i}^{n}\right)^{2}}{T-1}}
$$

and the average standard deviation of $M$ random portfolios, each of size $n$ is

$$
\overline{\sigma^{n}}=\sum_{i=1}^{M} \frac{\sigma_{i}^{n}}{M}
$$

Despite its drawbacks, standard deviation is the most used measure of risk in the finance literature. $^{14}$

\subsection{Expected Shortfall}

Expected shortfall (ES) satisfies the subadditivity condition and provides a natural extension to VaR. In fact, expected shortfall at level $\alpha, E S_{\alpha}$, can be defined as the expected value of the losses exceeding $\operatorname{VaR}_{\alpha}{ }^{15}$

We estimate expected shortfall from the portfolio returns. Let $R_{i, t, \alpha}^{n}$ be the empirical $\alpha$ th quantile. We define:

$$
\Omega_{i}^{n} \equiv E S_{\alpha, i}^{n}=-\frac{1}{T_{\alpha}} \sum_{t=1}^{T} R_{i, t}^{n} \mathbf{1}\left(R_{i, t}^{n} \leq R_{i, t, \alpha}^{n}\right)
$$

where $\mathbf{1}()=$.1 if $R_{i, t}^{n} \leq R_{i, t, \alpha}^{n}$ and 0 otherwise, and $T_{\alpha}$ denotes the number of $R_{i, t}^{n}$ no greater than $R_{i, t, \alpha}^{n}$.

We choose expected shortfall at the $1 \%$ level, $E S_{1 \%}$, as our measure of downside risk. ${ }^{16}$ When we estimate extreme risk measures, we are faced with a dilemma. We realize that market conditions change from one year to the next and so do the estimates of extreme measures.

\footnotetext{
${ }^{13}$ Although the formula in (7) is not adjusted for possible serial correlation (e.g., see French et al., 1987), we use this unadjusted measure as our benchmark both to compare with previous research on diversification and as the measure most frequently used by practitioners.

${ }^{14}$ We have also estimated our results using equation (5) with mean absolute deviation (MAD), median absolute deviation, and variance as measures of risk. These results are similar to those obtained with SD.

${ }^{15}$ If the underlying distribution for portfolio returns, $X$, is a continuous distribution then the expected shortfall is defined by $\left.E S_{\alpha}(X)=E\left[-X \mid X \leq-\operatorname{VaR}_{\alpha}(X)\right)\right]$. See Artzner et al., 1997; Annaert et al., 2009. For an excellent summary of risk measures see also Szego, 2002.

${ }^{16}$ In addition, we have obtained results using equation (5) with $E S_{10 \%}, E S_{5 \%}$ (using the same estimation procedure as for $E S_{1 \%}$ ) as well as lower partial moments (e.g., semi-variance). These results are similar to those obtained with the SD measure. However, focusing on extreme (black swan) events, $E S_{1 \%}$ yields considerably different results. This suggests that measures that focus on the extreme tails provide intrinsically different results than measures that utilize the larger portion of the distribution.
} 
Taking one year as a sub-period provides us on average with 250 daily observations sufficient to get a sensible historical estimate for $E S_{10 \%}$ or $E S_{5 \%}$. However, this sample size is not nearly enough to get a good historical estimate for $E S_{1 \%}$. Even if we take a rolling 3 year period and increase our sample to approximately 750 daily observations, the estimate of the $E S_{1 \%}$ is not satisfactory. Instead, we use a model-based simulation approach to increase the size of the sample for the particular subperiod in order to get a more reliable estimate. For each $n=1 . . N$ and each portfolio draw $m=1 . . M$ in each annual period from 1975 to 2011 and for each country, we perform GARCH filtration by using the GJR(1,1) model (Glosten et al., 1993) as our parametric benchmark for each of the simulated portfolios. By adopting this model we account for some stylised facts commonly attributed to financial time series. Namely, we control for autoregressive and conditional heteroskedasticity and the asymmetry in the conditional variances. In addition, by estimating the GJR model with $t$-distributed disturbances, we compensate for the presence of fat tails in equity portfolio returns. Once we estimate the model parameters, we standardise the residuals by the estimated conditional standard deviation to obtain a zero mean and unit variance disturbance. We use a semiparametric approach to estimate the distribution of these standardised residuals: the $10 \%$ lower and upper tails are estimated parametrically by fitting a Generalized Pareto Distribution using the peak over threshold (POT) approach (Pickands, 1975; Davison and Smith, 1990). We estimate the middle, 10\%-90\%, of the distribution non parametrically using normal kernel smoothing. We sample the residuals from the resulting estimated distributions which we then use in the estimated GJR $(1,1)$ models to obtain simulated observations. This allows us to simulate samples of lengths greater than the 250 trading days in a typical year. We find that 10,000 observations give us a reliable estimate of $E S_{1 \%} \cdot{ }^{17}$

\subsection{Terminal Wealth Standard Deviation}

Similar to O'Neal (1997), Brands and Gallagher (2005) and Benjelloun (2010) we use terminal wealth standard deviation (TWSD) as one of the risk measures. ${ }^{18}$ The advantage of using this risk measure is that while it is independent of the data frequency within the investment horizon, it does rely on the length of the investment horizon.

The terminal wealth of the $n$-stock equally weighted random portfolio $i$ at time $t$ is defined as

$$
T W_{i}^{n}=\sum_{t=1}^{T} R_{i, t}^{n}
$$

and the terminal wealth standard deviation can be expressed as

$$
T W S D^{n}=\sqrt{\sum_{i=1}^{M} \frac{\left(T W_{i}^{n}-\overline{T W^{n}}\right)^{2}}{M-1}}
$$

\footnotetext{
${ }^{17}$ We performed simulations to check the convergence of $E S_{1 \%}$ for sample lengths from 250 to 50,000 in 250 increments. Results are available upon request.

${ }^{18}$ They use simple returns and compute terminal wealth as $T W_{i}^{n}=\prod_{t=1}^{T}\left(1+R_{i, t}^{n}\right)$.
} 

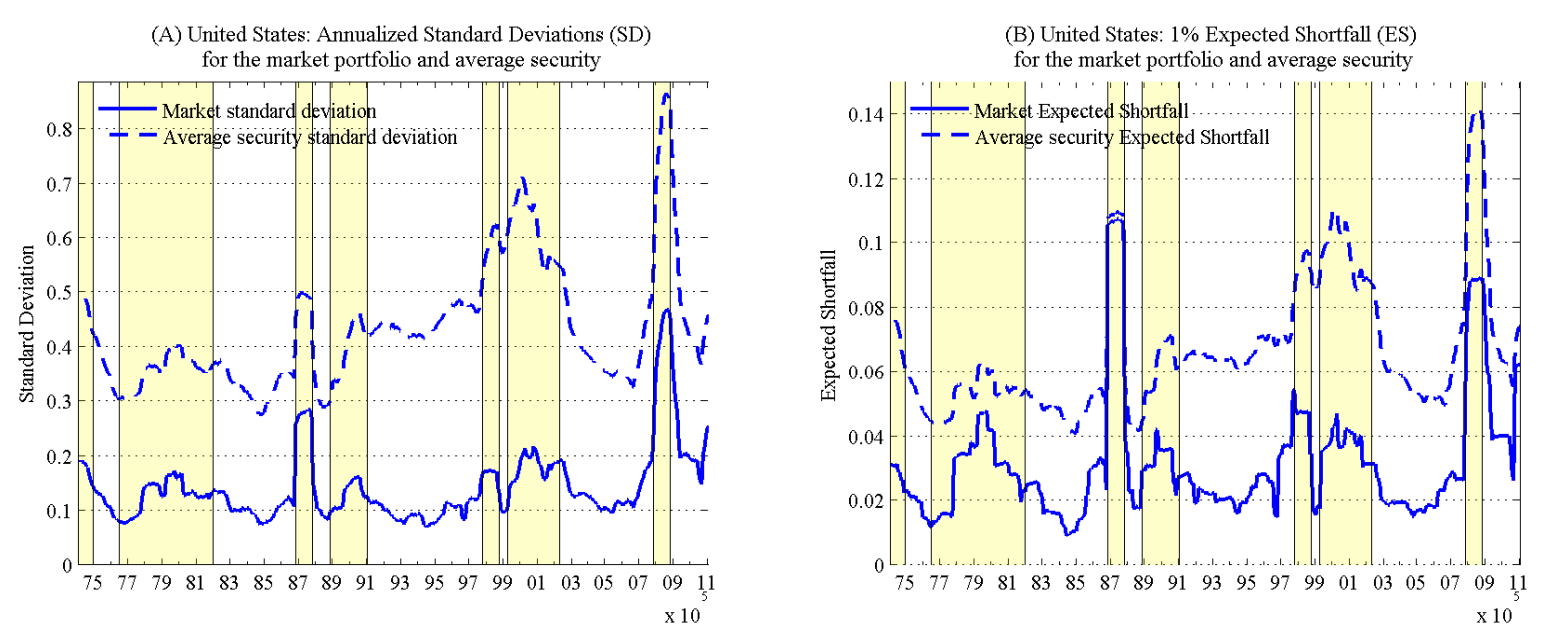

$\times 10$

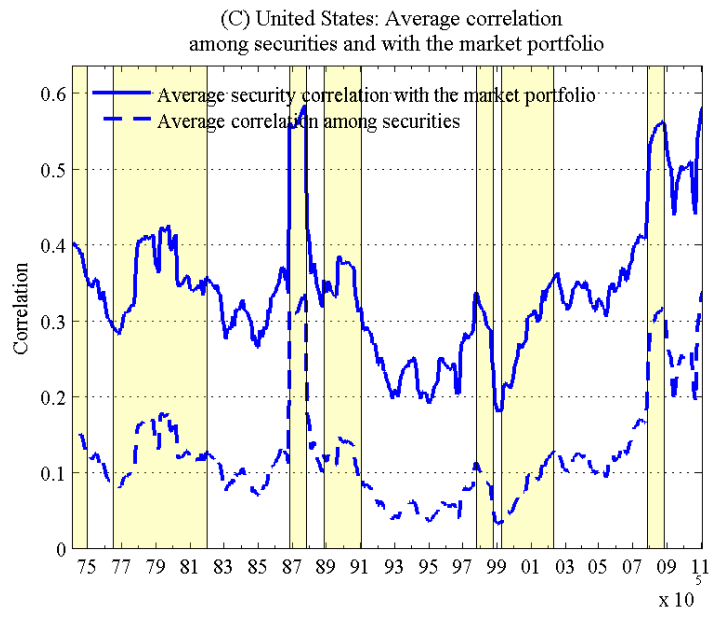

Figure 3: United States. In panel (A) the solid line shows the annualized standard deviation within each month of daily market returns based on the past 12 months' returns. The dashed line represents the average security standard deviation. Panel (B) depicts $E S_{1 \%}$ of the market portfolio (solid line) and the average security $E S_{1 \%}$ (dashed line). Panel (C) shows the average security correlation with the market portfolio (solid line) and the average correlation among securities (dashed line). Shaded regions in the figure represent periods of crises and correspond to events presented in Table 2.

where $\overline{T W^{n}}=\sum_{i=1}^{M} \frac{T W_{i}^{n}}{M}$ is the average terminal wealth over $M$ portfolios. ${ }^{19}$ Thus, the TWSD risk measure accounts for the volatility of terminal wealth.

\section{Results}

Table 1 and Figures 3 and 4 summarize our findings for the US market. It is interesting to note that in 2008 (see Figure 3.A), the average security standard deviation was only two times the standard deviation of the market, due to the fact that the overall market risk was one of

\footnotetext{
${ }^{19}$ Adopting the idea behind the Sortino measure that deviations above the market terminal wealth should not be penalized and following O'Neal (1997), we calculate the terminal wealth standard semi-deviation (TWSSD). We find that the number of stocks required in an optimal portfolio is similar to our results using TWSD as a measure of risk.
} 


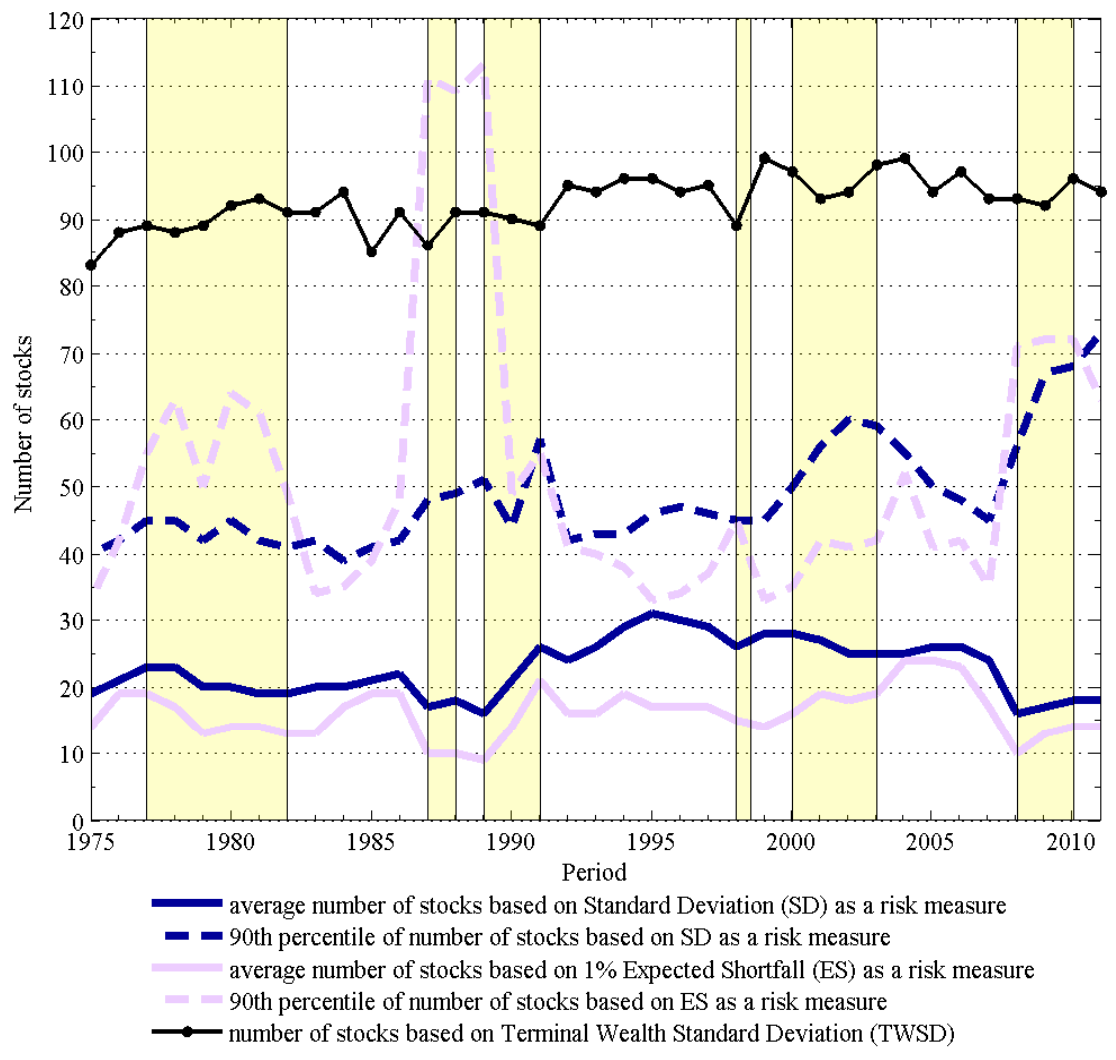

Figure 4: United States. Recommended portfolio size to achieve $90 \%$ reduction in diversifiable risk. The solid dark line represents the number of stocks recommended for an average investor to achieve $90 \%$ reduction in diversifiable risk when standard deviation is used as a risk measure. To achieve this reduction $90 \%$ of the time, portfolio size is depicted by the dashed dark line. Similarly, for investors concerned with extreme risk and using $E S_{1 \%}$ as the risk measure, the portfolio size for an average investor is depicted by the solid light line and the size of the portfolio that assures this reduction $90 \%$ of the time is shown by the dashed light line. For investors concerned with terminal wealth standard deviation, our recommended portfolio size is shown by the dark solid line with circles. Shaded regions in the figure represent periods of crises and correspond to events presented in Table 2. 

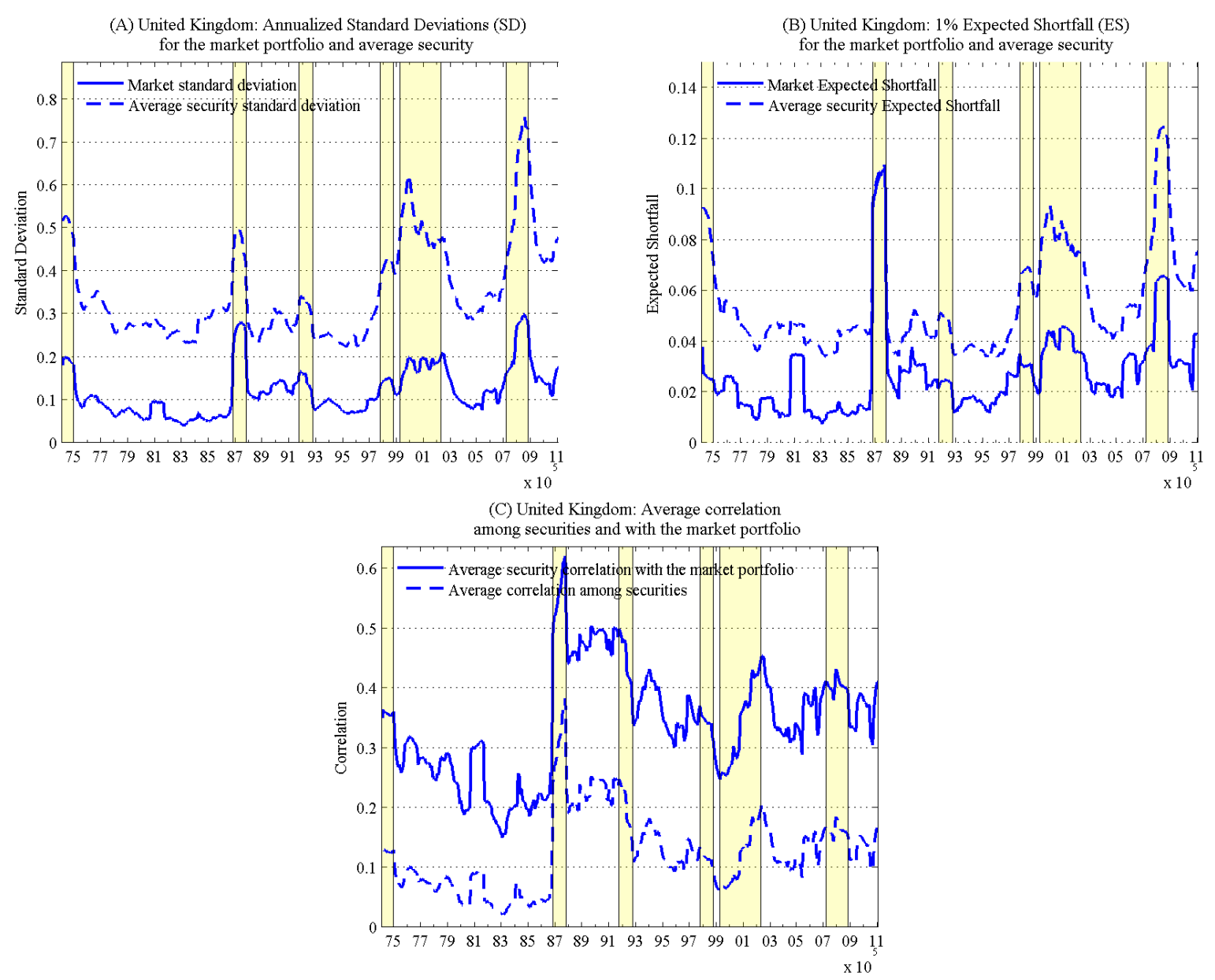

Figure 5: United Kingdom. In panel (A) the solid line shows the annualized standard deviation within each month of daily market returns based on the past 12 months' returns. The dashed line represents the average security standard deviation. Panel (B) depicts $E S_{1 \%}$ of the market portfolio (solid line) and the average security $E S_{1 \%}$ (dashed line). Panel (C) shows the average security correlation with the market portfolio (solid line) and the average correlation among securities (dashed line). Shaded regions in the figure represent periods of crises and correspond to events presented in Table 2.

the highest. Similarly, Figure 3.B depicts the average security $E S_{1 \%}$ relative to $E S_{1 \%}$ of the overall market. For the average security, $E S_{1 \%}$ was closer to the market's during the 1987 crash, but not as close to the market's $E S_{1 \%}$ during the 2008-2009 Global Financial Crisis (GFC). This difference may be due to the rise of globalization since 1987 when many more international firms were listed on US markets, and the sectoral composition of US markets was increasingly diversified. Consistent with Campbell et al. (2001), we observe that an increase in idiosyncratic risk means that more stocks are required to diversify portfolios. This is coupled with declining average correlations among stocks. We observe that the higher the correlations among stocks in the market, the lower the number of stocks required to diversify the portfolio of an average investor. This happens because in periods when correlations among stocks are high, selecting fewer stocks will achieve the desired level of idiosyncratic risk reduction (the market is comprised of these highly correlated stocks), and since we are diversifying idiosyncratic risk, and in a perfectly diversified portfolio, the risk 


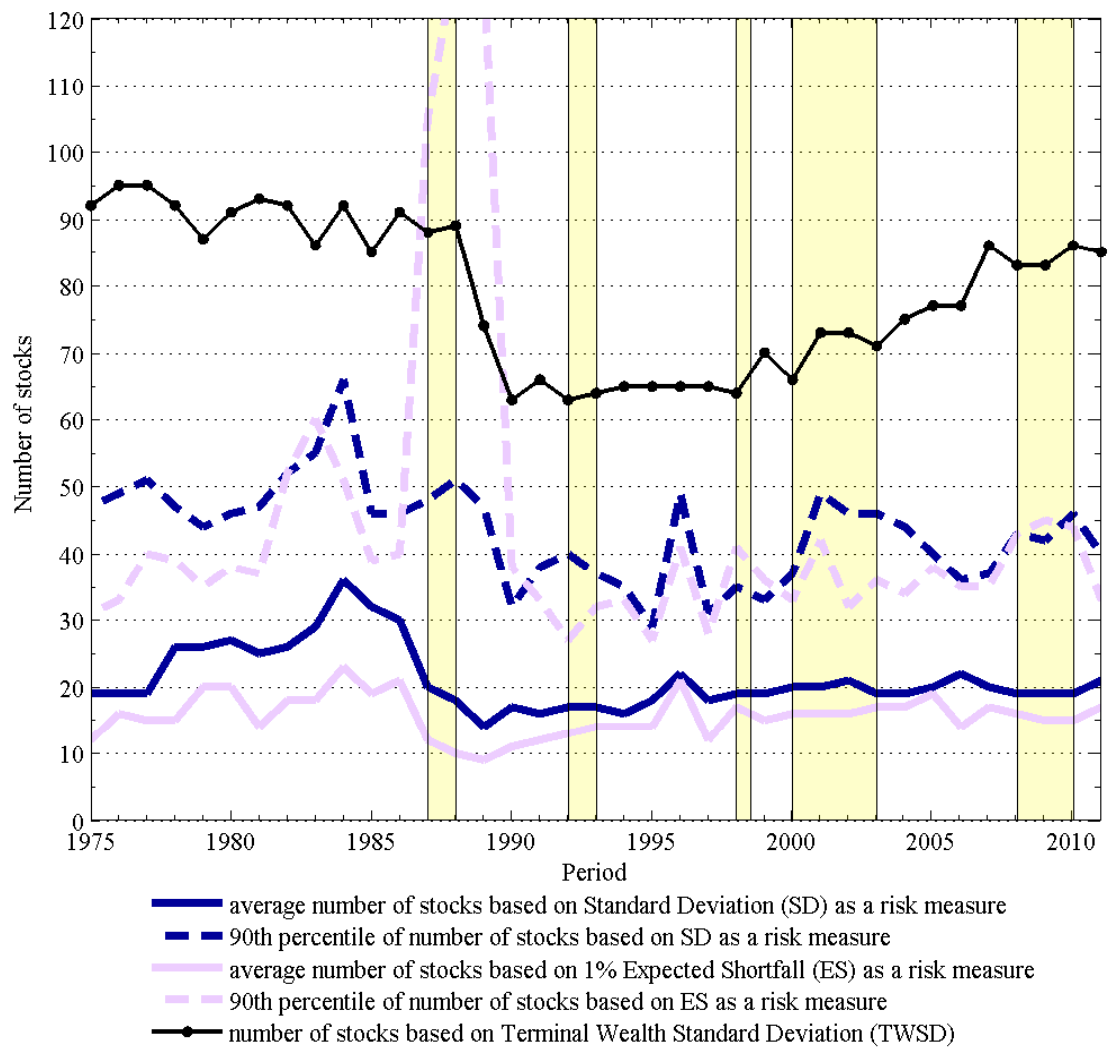

Figure 6: United Kingdom. Recommended portfolio size to achieve 90\% reduction in diversifiable risk. The solid dark line represents the number of stocks recommended for an average investor to achieve $90 \%$ reduction in diversifiable risk when standard deviation is used as a risk measure. To achieve this reduction $90 \%$ of the time, portfolio size is depicted by the dashed dark line. Similarly, for investors concerned with extreme risk and using $E S_{1 \%}$ as the risk measure, the portfolio size for an average investor is depicted by the solid light line and the size of the portfolio that assures this reduction $90 \%$ of the time is shown by the dashed light line. For investors concerned with terminal wealth standard deviation, our recommended portfolio size is shown by the dark solid line with circles. Shaded regions in the figure represent periods of crises and correspond to events presented in Table 2. 

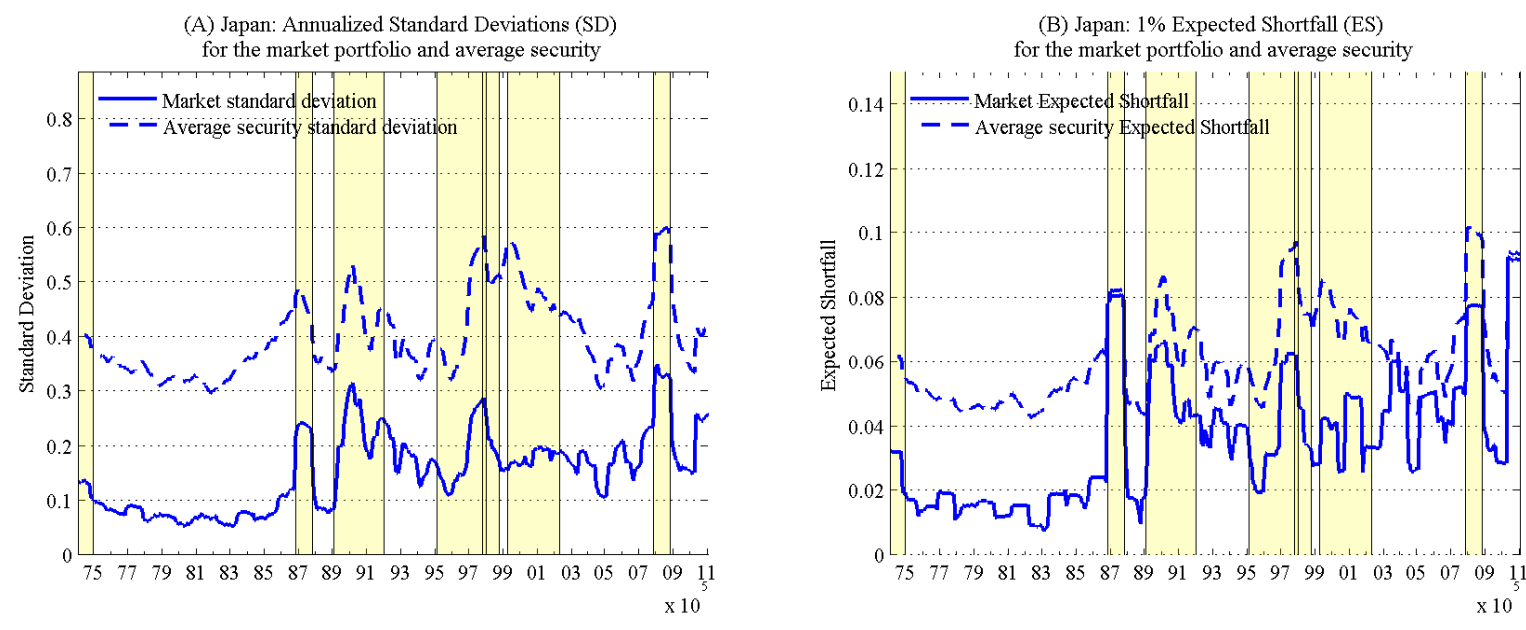

$\times 10$

among securities and with the market portfolio

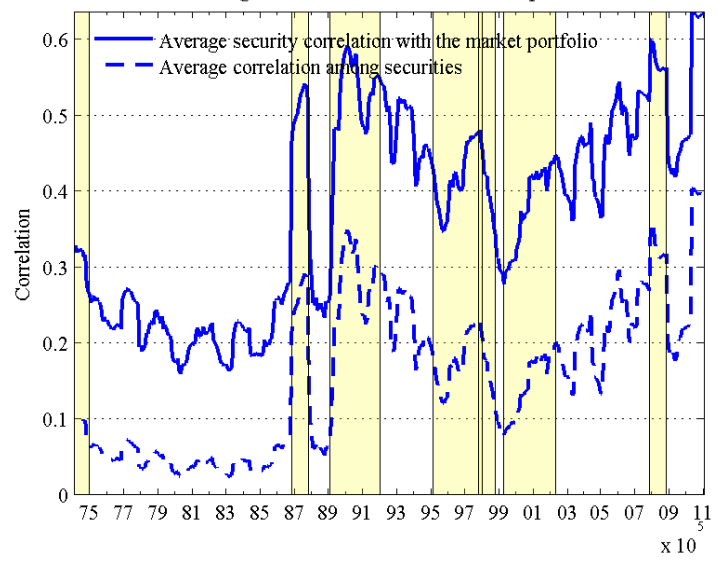

Figure 7: Japan. In panel (A) the solid line shows the annualized standard deviation within each month of daily market returns based on the past 12 months' returns. The dashed line represents the average security standard deviation. Panel (B) depicts $E S_{1 \%}$ of the market portfolio (solid line) and the average security $E S_{1 \%}$ (dashed line). Panel (C) shows the average security correlation with the market portfolio (solid line) and the average correlation among securities (dashed line). Shaded regions in the figure represent periods of crises and correspond to events presented in Table 2.

will consist only of market risk.

For example, in the US, between 1991 and 2001 (Fig 3.A), the gap between average security standard deviation and market standard deviation widened, while the average correlations among stocks declined (Figure 3.C), resulting in an increased number of stocks required to diversify a portfolio (Figure 4 solid dark line). In the period 2002 to 2007, the gap between average security standard deviation and market standard deviation began to shrink (Figure 3.A), average correlations among stocks started to increase (Figure 3.C), resulting in a declining required number of stocks (Figure 4 solid dark line). Between 2008 and 2011, a period characterized by the GFC, the gap between average security standard deviation and market standard deviation remained narrow, average correlations spiked up to a level comparable to the period of the flash crash of 1989, resulting in a much reduced number of stocks required to diversify a portfolio (Figure 4). When ES is used as a measure of risk rather than $\mathrm{SD}$, we observe similar trends in every period but with a reduced number 


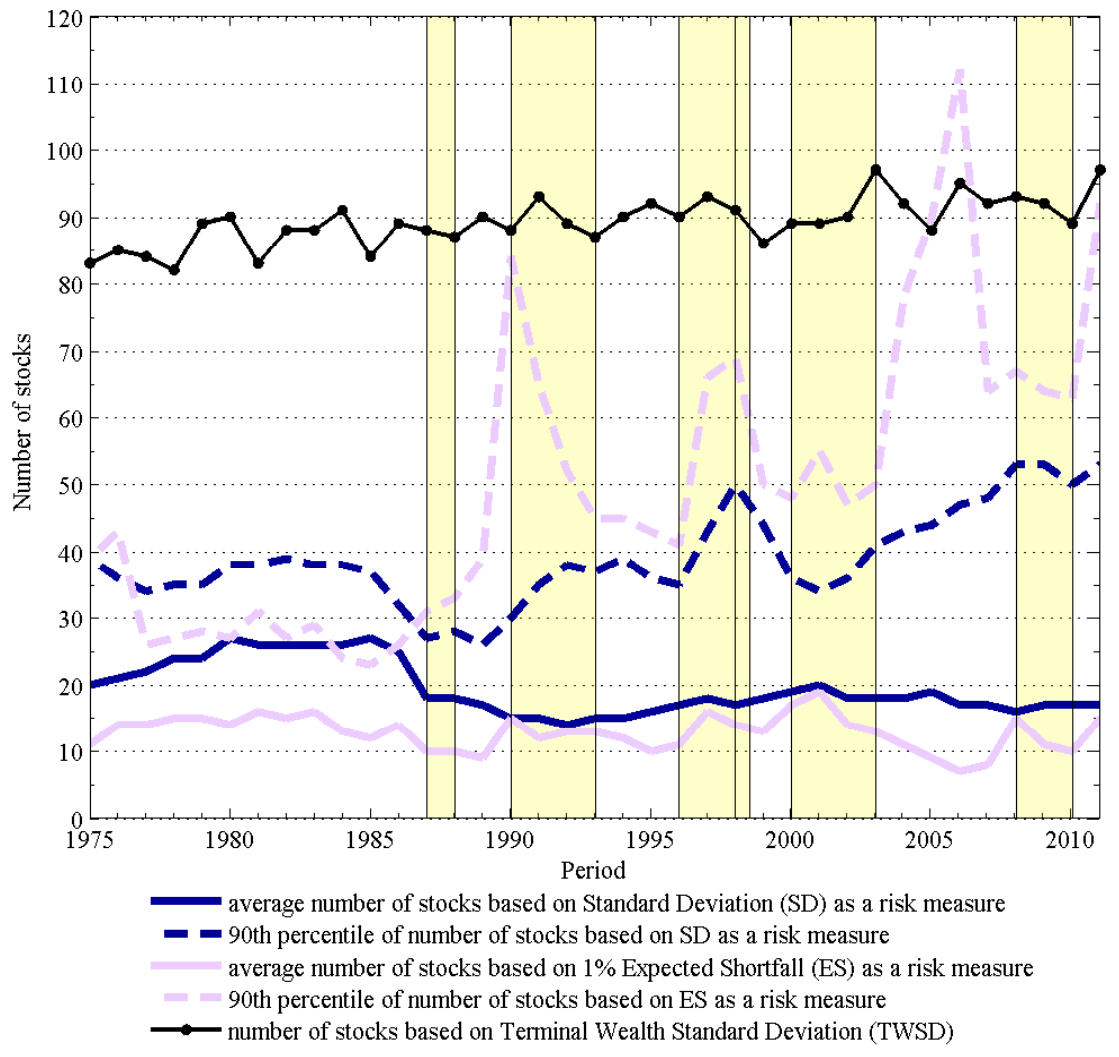

Figure 8: Japan. Recommended portfolio size to achieve $\mathbf{9 0 \%}$ reduction in diversifiable risk. The solid dark line represents the number of stocks recommended for an average investor to achieve $90 \%$ reduction in diversifiable risk when standard deviation is used as a risk measure. To achieve this reduction $90 \%$ of the time, portfolio size is depicted by the dashed dark line. Similarly, for investors concerned with extreme risk and using $E S_{1 \%}$ as the risk measure, the portfolio size for an average investor is depicted by the solid light line and the size of the portfolio that assures this reduction $90 \%$ of the time is shown by the dashed light line. For investors concerned with terminal wealth standard deviation, our recommended portfolio size is shown by the dark solid line with circles. Shaded regions in the figure represent periods of crises and correspond to dates presented in Table 2. 

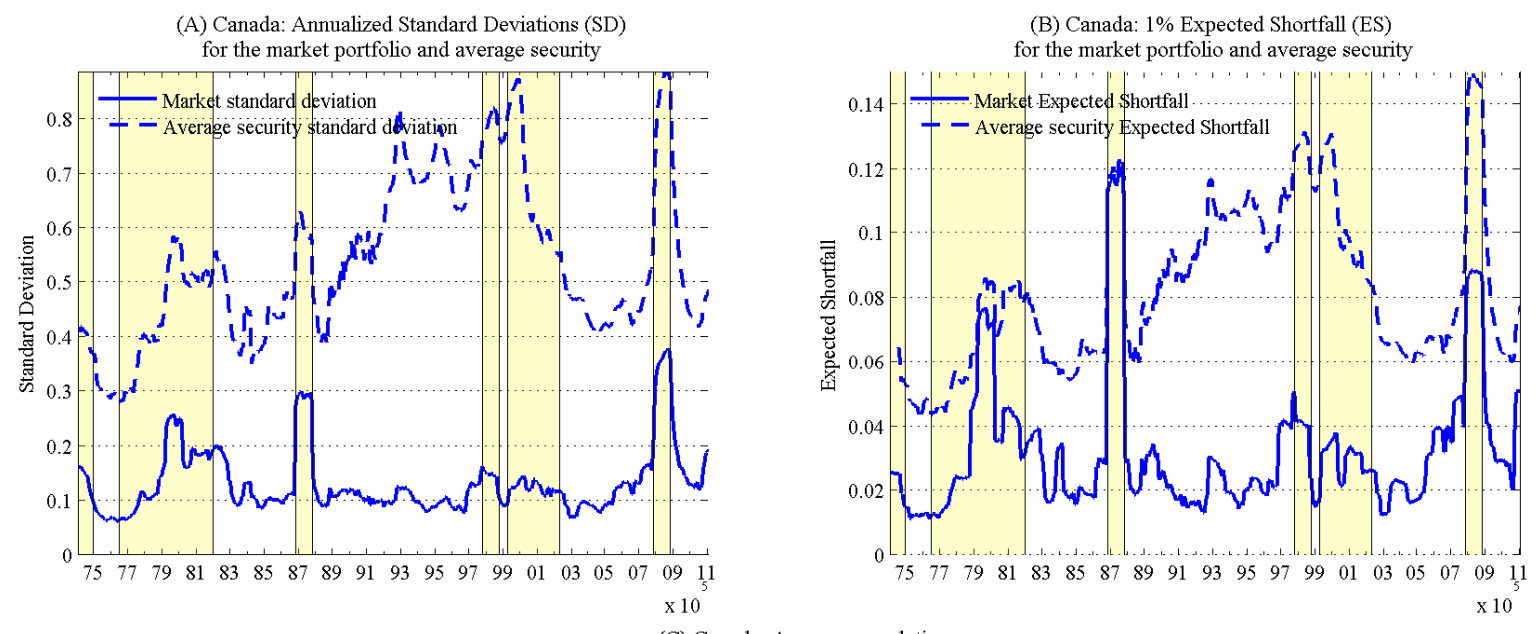

(C) Canada: Average correlation

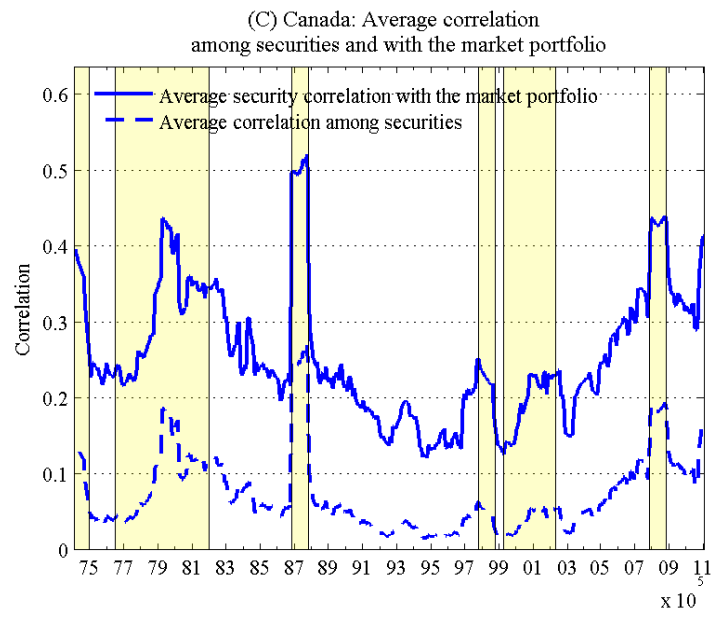

Figure 9: Canada. In panel (A) the solid line shows the annualized standard deviation within each month of daily market returns based on the past 12 months' returns. The dashed line represents the average security standard deviation. Panel (B) depicts $E S_{1 \%}$ of the market portfolio (solid line) and the average security $E S_{1 \%}$ (dashed line). Panel (C) shows the average security correlation with the market portfolio (solid line) and the average correlation among securities (dashed line). Shaded regions in the figure represent periods of crises and correspond to events presented in Table 2.

of stocks required to diversify a portfolio (Figure 4 solid light vs. solid dark lines).

We note from Figure 3.C (dashed line) a downward trend in average correlations among stocks in the US from 1975 to 2000 and the reversal of this trend between 2000 and 2011, including the period 2002 to 2007 when the economy was not in crisis. The declining trend was first reported by Campbell et al. for the period 1960 to 2000 (see Figure 5.A in Campbell et al., 2001, p.24 ), but we find that this trend reversed itself soon after their paper was published. After 2000, increased correlations among stocks made it easier to achieve portfolio diversification with a small number of stocks, as can be seen in Figure 4. From Figure 3.A we observe that in the period 1975-2007 market volatility has been relatively stable (solid line) whereas the average security volatility has increased since $1989 .{ }^{20}$

\footnotetext{
${ }^{20}$ This is consistent with Campbell et al. (2001).
} 


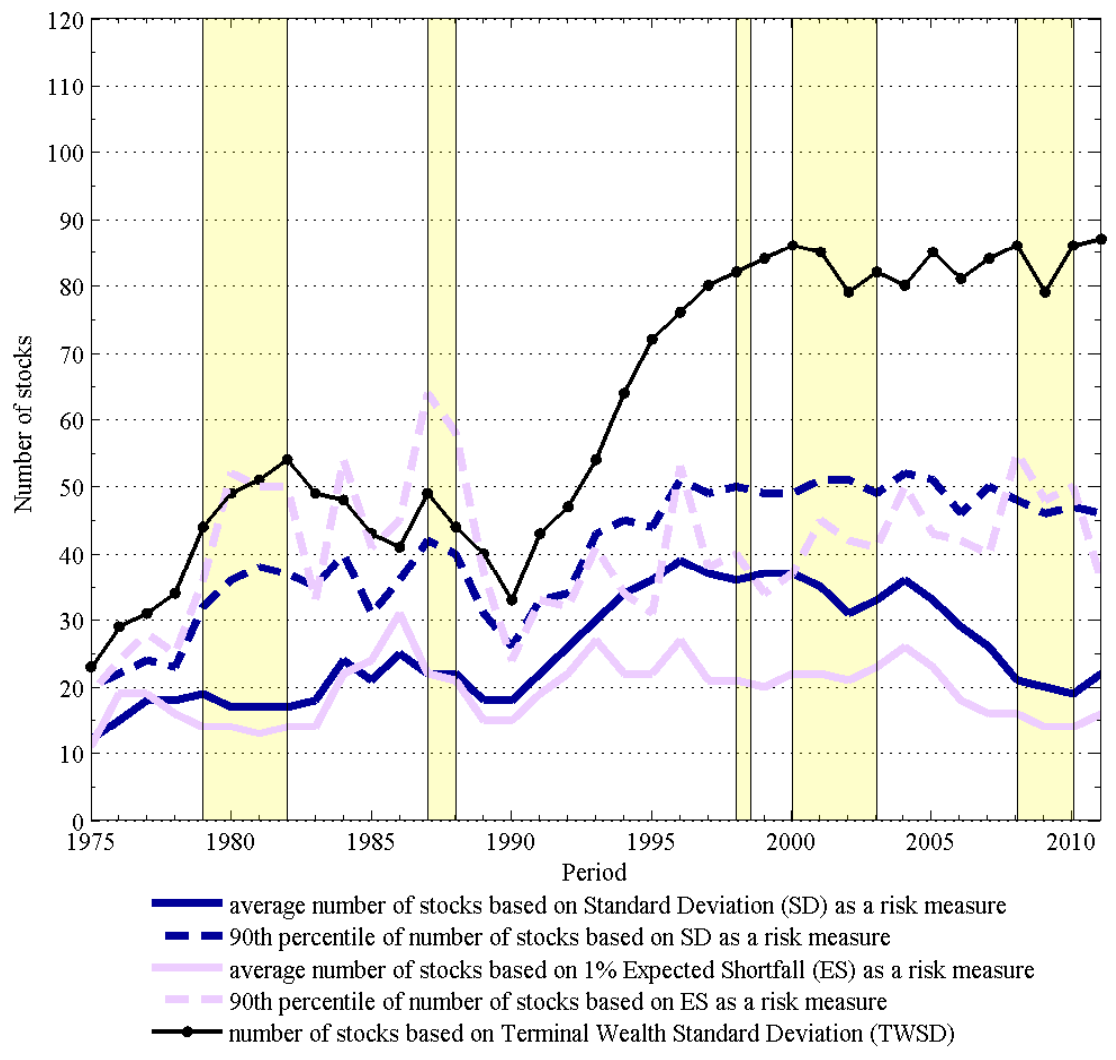

Figure 10: Canada. Recommended portfolio size to achieve $\mathbf{9 0 \%}$ reduction in diversifiable risk. The solid dark line represents the number of stocks recommended for an average investor to achieve $90 \%$ reduction in diversifiable risk when standard deviation is used as a risk measure. To achieve this reduction $90 \%$ of the time, portfolio size is depicted by the dashed dark line. Similarly, for investors concerned with extreme risk and using $E S_{1 \%}$ as the risk measure, the portfolio size for an average investor is depicted by the solid light line and the size of the portfolio that assures this reduction $90 \%$ of the time is shown by the dashed light line. For investors concerned with terminal wealth standard deviation, our recommended portfolio size is shown by the dark solid line with circles. Shaded regions in the figure represent periods of crises and correspond to events presented in Table 2. 

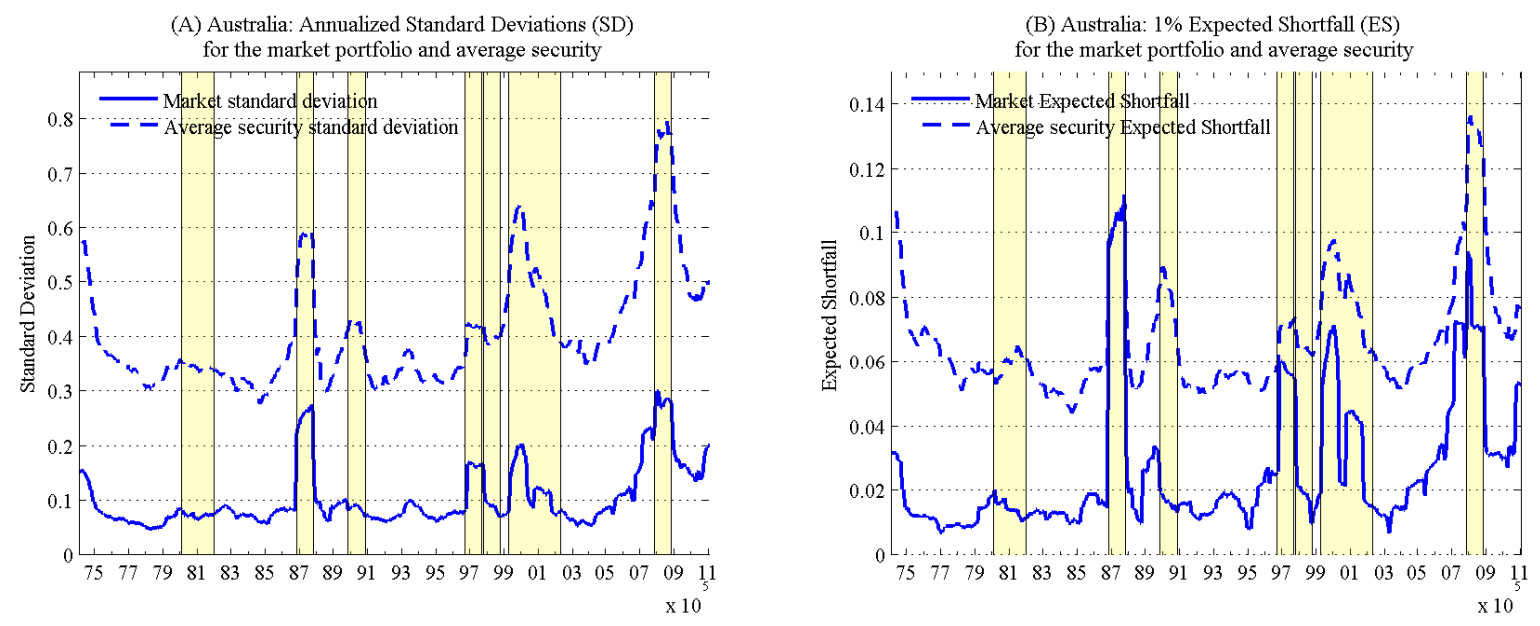

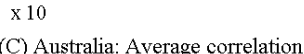

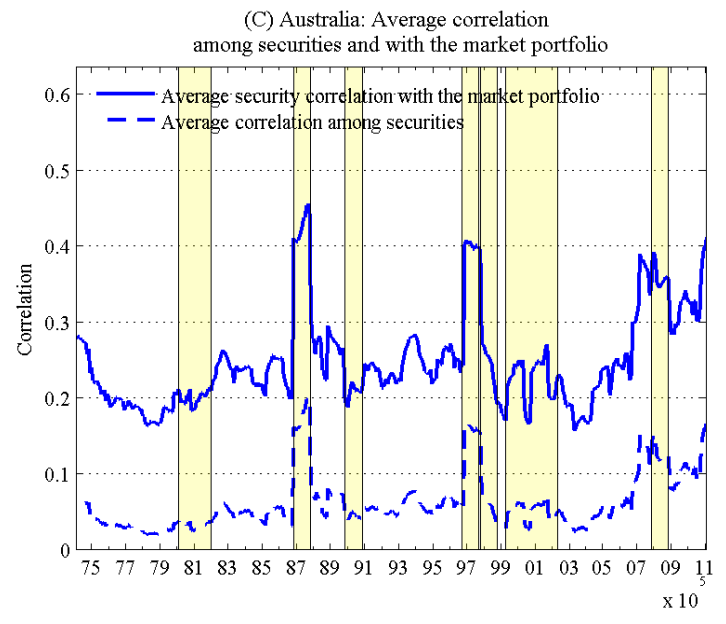

Figure 11: Australia. In panel (A) the solid line shows the annualized standard deviation within each month of daily market returns based on the past 12 months' returns. The dashed line represents the average security standard deviation. Panel (B) depicts $E S_{1 \%}$ of the market portfolio (solid line) and the average security $E S_{1 \%}$ (dashed line). Panel (C) shows the average security correlation with the market portfolio (solid line) and the average correlation among securities (dashed line). Shaded regions in the figure represent periods of crises and correspond to events presented in Table 2.

Figure 4 and Table 1 (columns 1 to 3 ) show the average number of stocks required to achieve $90 \%$ reduction in diversifiable risk as defined by equation (5). Using standard deviation as the measure of risk, an average investor (solid dark line) must hold from 16 to 31 stocks (see Table 1 column 1). This result is stable across all years with only a slight increase in the number of stocks required in the period 1990 to 2007. Looking at the dashed dark line in Figure 4, we note that an investor who wants to achieve a $90 \%$ diversifiable risk reduction with $90 \%$ certainty instead of on average, should hold a portfolio comprised of 39-73 stocks (see also Table 1 column 1a). The number of stocks to achieve this level of certainty, i.e., to reduce $90 \%$ of diversifiable risk $90 \%$ of the time, increases during periods when markets are in financial distress (for example, in Table 1 column 1a 49-51 stocks in 


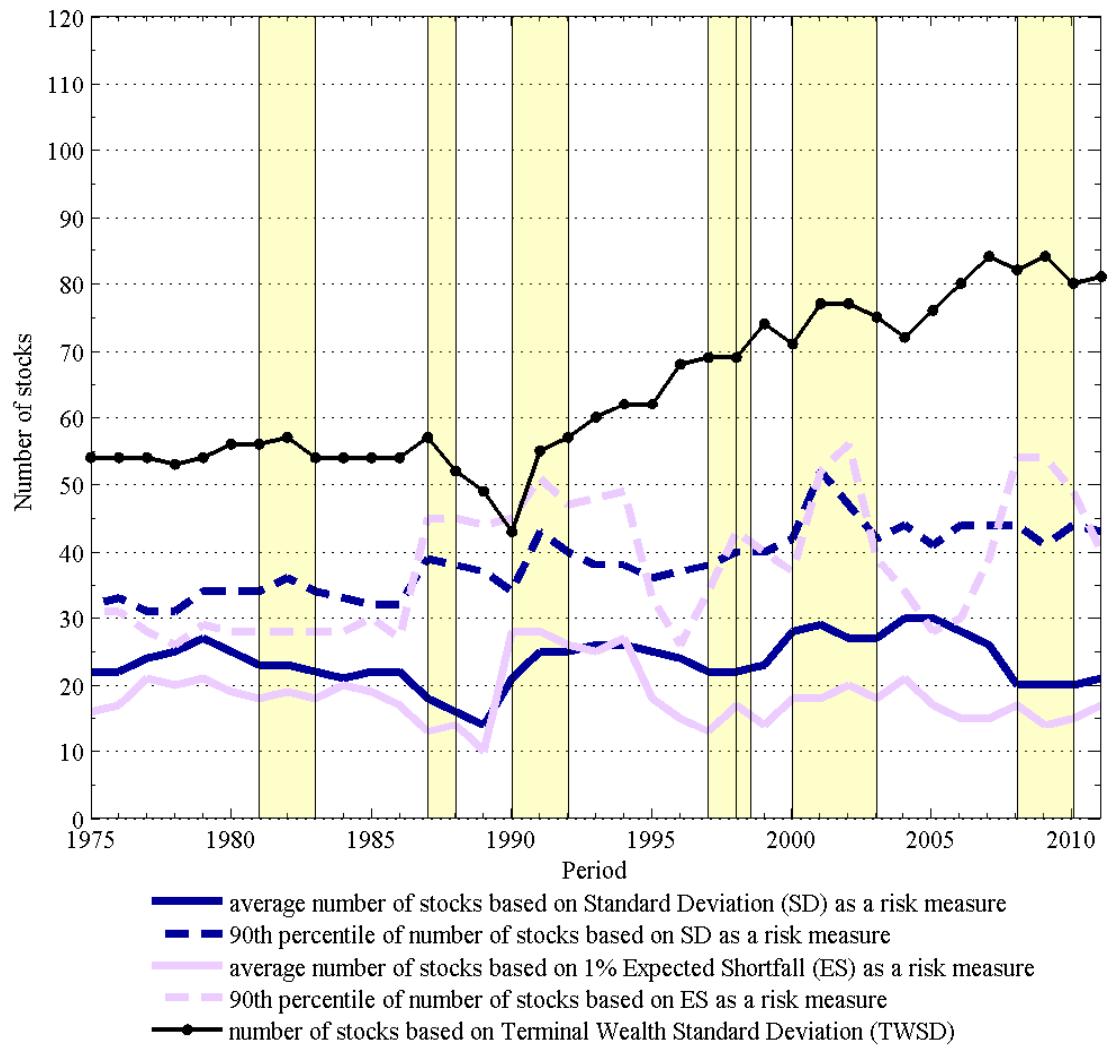

Figure 12: Australia. Recommended portfolio size to achieve $\mathbf{9 0 \%}$ reduction in diversifiable risk. The solid dark line represents the number of stocks recommended for an average investor to achieve $90 \%$ reduction in diversifiable risk when standard deviation is used as a risk measure. To achieve this reduction $90 \%$ of the time, portfolio size is depicted by the dashed dark line. Similarly, for investors concerned with extreme risk and using $E S_{1 \%}$ as the risk measure, the portfolio size for an average investor is depicted by the solid light line and the size of the portfolio that assures this reduction $90 \%$ of the time is shown by the dashed light line. For investors concerned with terminal wealth standard deviation, our recommended portfolio size is shown by the dark solid line with circles. Shaded regions in the figure represent periods of crises and correspond to events presented in Table 2. 
1988-1989 following the market crash in 1987, 50-60 stocks from 2000 to $2002^{21}$ right after the burst of the Dot Com Bubble, and 56-73 stocks in 2008-2011 during the GFC). During such periods, events which normally would not threaten a firm's survival might lead to bankruptcy or takeover. Thus, investors need a larger number of stocks to guard against diversifiable risk with this level of certainty.

From 1975 to 2011 (Figure 4 and Table 1 column 2), using $E S_{1 \%}$ as a measure of risk, the solid light line shows that average investors need to hold in their portfolios 10 stocks (in 1987-1988) to 24 stocks (in 2004-2005) to reduce the $E S_{1 \%}$ diversifiable risk by $90 \%$. However, Table 1 column $2 \mathrm{a}$ and the dashed light line in Figure 4 indicate that to achieve this reduction with $90 \%$ certainty for most years, a portfolio of 33 to 55 holdings is required, with exceptions in 1977-1981 (50-64 stocks), 1987-1989 (109-113 stocks) and 2008-2011 (6372 stocks). The solid line with circles (in Figure 4) represents the number of portfolio holding requirements using terminal wealth standard deviation as a measure of risk which is always higher than the number based on the standard deviation and $E S_{1 \%}$ measures. It is relatively constant throughout the period requiring on average holdings of 83-99 stocks (Table 1 column 3) to reduce the level of diversifiable risk by $90 \%$.

Turning our attention to the UK market results in Table 1, columns 4 to 6 and Figures 5 and 6, we observe that 1978-1986 was the period with the highest number of holdings in portfolios of an average investor concerned with standard deviation as a measure of risk (25-36 stocks in Table 1 column 4). After 1986, a relatively low number of stock holdings is required to achieve 90\% reduction in diversifiable risk (14-22 stocks). For UK investors concerned with standard deviation as a measure of risk (shown by the dark dashed line in Figure 6), it would have been advisable to hold 29-66 stocks to eliminate $90 \%$ of diversifiable risk with $90 \%$ assurance over the entire period (Table 1 column 4a). The results based on $E S_{1 \%}$ (Table 1 column 5) require, on average, holding 9-23 securities to achieve $90 \%$ diversification risk reduction. It is, however, apparent from Figure 6 that for an average investor the number of stocks required to achieve the $90 \%$ reduction in diversifiable risk based on $E S_{1 \%}$ is lower than when based on SD. To assure UK investors of achieving this level of risk reduction with $90 \%$ certainty based on the $E S_{1 \%}$ measure, anywhere from 27 to 60 stocks are advisable with the exception of the market crash in 1987 and the following two years where 105-129 stocks are recommended. Using TWSD as a risk measure, an average investor should have held 85-95 stocks to eliminate $90 \%$ of diversifiable risk from 1975 to 1988; 63-66 stocks, a substantially lower requirement, from 1990 to 1998; 66-86 stocks, a steadily increasing requirement from 1999 and 2011 (Table 1 column 6 and Figure 6, solid line with circles).

The correlation analysis we perform for the US carries over for the UK. In the period from 1975 to just before Black Monday 1987, the average correlation among stocks was the lowest and declining (Figure 5.C), resulting in an increasing number of stocks required in diversified portfolios (Figure 6 solid dark line). The sudden jump in the average correlations among stocks in 1987 and their slow decline until 2000 resulted in a drop in the number of stocks required for portfolio diversification (Figure 6 solid dark line).

Results for the Japanese financial market (Figures 7 and 8) present an interesting feature:

\footnotetext{
${ }^{21}$ In Table 2 we cross-reference the recommended portfolio sizes during crises.
} 
prior to 1987, average correlations and market volatility were among the lowest. During that period, we find a narrow difference between portfolio sizes needed to achieve diversification for an average investor compared to when this diversification is assured $90 \%$ of the time (Figure 8 difference between solid dark line and dashed dark line). This changes after 1986 when the difference grows considerably. The period is also characterized by an increased level in average correlations among stocks and increased volatility in the market (Figures 7 Panels C, A and B). From 1975 to 1986 using standard deviation as a risk measure, 20-27 stocks were needed, but to assure $90 \%$ certainty of the $90 \%$ risk reduction between 32-39 stocks were required. However, between 1987 and 2011 using standard deviation as a risk measure, 14-20 stocks were required, but to assure $90 \%$ certainty of the $90 \%$ risk reduction between 26-53 stocks were needed. We observe similar patterns when risk is measured as $E S_{1 \%}$. We define these contemporaneous gaps in portfolio size recommendations as $\Delta n$ (see Table 3 Panel D). For Japan, note that large gaps $(\Delta n)$ correspond to periods of high correlations $\left(\bar{\rho}_{i m}\right)$ and high market volatility $\left(\sigma_{m}\right)$. Japan experienced the lowest average correlations among stocks in the period 1975 to 1986, which coincides with the largest number of stocks recommended in a diversified portfolio for an average investor (Figure 8 solid dark line). Correlations among stocks steadily increase from 1986 to 1992 (Figure 7.C) while the number of stocks required for portfolio diversification declines (Figure 8 solid dark line). This period for Japan is marked by the bursting of the asset bubble and the First Gulf War. Between 1992 and 2001, average correlations trend down (Figure 7.C) while the number of stocks required for portfolio diversification increases. From 2001 and 2011, average correlations among stocks experience a sharp increase matched by a declining number of stocks required for portfolio diversification. When risk is measured as TWSD (Table 1 column 9 or Figure 8), however, the number of stocks required is stable across the 1975 to 2011 period ranging from 82 to 97 stocks.

For the Canadian market, in Table 1, columns 10-12 and Figure 10, we observe that between 1992 and 2005 the average investor needed to hold a higher number of stocks (2639 stocks) as did the investor wishing to reduce diversifiable risk with $90 \%$ certainty (3452 stocks) compared to the period 1975 to 1991. This is a consequence of higher average correlations among stocks in the earlier period compared to the later period (see Figure 9.C). The general trend is consistent with the US markets; however, the average US investor in the period from 1992 to 2006 required a portfolio consisting of 24 to 31 stocks to achieve a $90 \%$ reduction in diversifiable risk as measured by standard deviation, while the average Canadian investor required 26-39 stocks. Given the closeness of the US and Canadian economies, we are not surprised to find similarities between required portfolio holdings in the US and Canada compared to different requirements in the UK, Japan or Australia.

The recession period for Canada between 1992 to 2004 was marked by a wide gap between average security standard deviation and market standard deviation (Figure 9.A), the lowest average correlation among stocks (Figure 9.C), and the largest number of stocks required to diversify portfolio risk (Figure 10 solid dark line). When ES is used as a measure of risk, we observe similar trends in every period but with a reduced number of stocks required to diversify a portfolio, except during the flash crash on Black Monday 1987 (Figure 10 solid light and dark lines).

For Australian investors concerned with standard deviation as a measure of risk, portfolios on average require 14-30 stocks (Table 1, column 13 and Figure 12, solid dark line). But from 
1991 to 2007, investors had to hold a slightly larger portfolio (22-30 stocks) to achieve $90 \%$ in diversifiable risk on average. Between 1975 and 1987, to assure the $90 \%$ reduction 90\% of the time, Australian investors needed to hold 31-39 stocks. Between 1988 to 2011 portfolio size increased to 34-52 stocks (Table 1, column 13a and Figure 12, dashed dark line). Consistent with the results from analyzing other countries, the portfolio size recommendations for an average Australian investor based on $E S_{1 \%}$ are generally lower by $5-7$ stocks over the entire period when compared with SD. To achieve $90 \%$ reduction in risk with $90 \%$ certainty, a similar pattern emerges except when financial markets are in distress.

Australia prominently displays the negative relationship between average correlation among stocks and the number of stocks required for portfolio diversification. At the same time the gap between average security standard deviation and market standard deviation (Fig 11.A) remains relatively stable through the whole period. The periods of financial distress (1987-1989, 2008-2011) and the Asian financial crisis (1997-1998) are characterized by the highest average correlations (Figure 11.C) and a reduced number of stocks required for portfolio diversification (Figure 12 solid dark line). When ES is used as a measure of risk, we observe similar trends in every period but with a reduced number of stocks required to diversify a portfolio, except during the First Gulf War in 1990-1992 (Figure 12 solid light and dark lines).

We note that average correlations among stocks differ from country to country (Panels $\mathrm{C}$ in Figures 3, 5, 7, 9, and 11 and Panel $\mathrm{B}$ in Table 3). On average, we find the highest correlations among individual stocks (see Table 3 Panel B) in Japan (0.16), followed by the US (0.13) and the UK (0.13). The lowest correlations among stocks are in Canada (0.08) and Australia (0.07). We confirm that the higher the correlation among stocks in the market, the lower the number of stocks required to diversify the portfolio for an average investor (see Table 3 Panels A and B). For each country, when market volatilities and correlations are lower, recommended portfolio sizes are higher. Conversely, when volatilities and correlations are higher fewer stocks are required to obtain most diversification benefits (Table 3 Panel C). For example, in the US, small portfolios of less than 19 stocks are recommended in periods with an average correlation of 0.50 and an increased market volatility of $23.7 \%$. In contrast, larger portfolios of 26 stocks or more are recommended in periods with an average correlation of 0.24 and a market volatility of $11.5 \%$. In Table 3 Panel D we show the spread between the number of stocks required to assure investors of the desired level of diversification $90 \%$ of the time and the portfolio size for the average investor (defined as $\triangle n$ ). ${ }^{22}$ For the US, a spread of fewer than 20 stocks $(\triangle n<20$ in Table 3 Panel D) is associated with market volatility of $10.9 \%$ and an average correlation of 0.27 ; a spread of more than 31 stocks is associated with a market volatility of $23.7 \%$ and an average correlation of 0.45 . One exception is the UK, where spreads of fewer than 17 stocks are associated with an average correlation of 0.34 whereas for spreads greater than 27 stocks, the average correlation is only marginally higher (0.36). This means that in periods of high market volatility and large correlations among stocks, conservative investors need to add more stocks to the portfolios recommended for average investors to assure a reduction in risk $90 \%$ of the time.

During periods of extreme market volatility or market crashes (black swan events), it

\footnotetext{
${ }^{22}$ Refer to the difference between the dashed and solid lines in Figures 4, 6, 8, 10 and 12.
} 
is not surprising that when we use measures of extreme risk such as $E S_{1 \%}$, the portfolio size requirements to achieve the desired level of diversification with $90 \%$ certainty increase dramatically, even doubling for the US and the UK (refer to Table 1, 'Average' row at bottom vs. columns 2a, 5a, 8a, 11a, and 14a). Using TWSD as a risk measure (Table 1 column 15 and Figure 12, solid line with circles), in the period 1975-1988, an average Australian investor would have held 52-57 stocks (compared to 85-95 in the UK) to eliminate $90 \%$ of diversifiable risk, with a substantially lower requirement (43-49 stocks) in 1989-1990 and incrementally and steadily increasing portfolio sizes from 1991 (55 stocks) to 2011 (81 stocks).

The period from 1975 to 2011 allows us to account for some significant events in financial market history. We conclude that portfolio sizes are determined by the particular risk measure used and by market conditions including correlations among stocks. We identify two types of crises, general drops in the market (1987 and 2008-2011) and industry specific meltdowns (2000-2002). ${ }^{23}$ Such crises are characterized by a few common features. In the case of market crashes, we note increased market risk measured by SD and especially $E S_{1 \%}$ coupled with greatly increased average correlations among securities as well as the correlation of the average security with the market portfolio (see Figures 3, 5, 7, 9, 11). During market crashes in the US, Figure 4 (solid dark line) shows that the number of stocks required for an average investor to obtain a $90 \%$ reduction in diversifiable risk using standard deviation as a measure decreases. But at the same time, we observe an increase in the number of stocks required to achieve the same level of diversification but with $90 \%$ confidence. For the average US investor, Tables 1 and 2 confirm that during major stock market crashes $(1987,1989$, and 2008) the number of stocks required to eliminate $90 \%$ of diversifiable risk was the lowest (16-17 stocks when risk is measured by SD and 9-10 stocks when risk is measured by $E S_{1 \%}$ ). The number of stocks required to achieve the same level of diversification but with $90 \%$ confidence was the highest across all periods when risk is measured as $E S_{1 \%}$ (71-113 stocks). This result generally holds across all five markets.

In the case of industry specific meltdowns, such as the collapse of LTCM and the bursting of the Dot Com bubble, the market experienced high volatility. The average correlations among securities within the market and with the market portfolio, however, were among the lowest (Figures 3, 5, 7, 9, 11). As shown for the US in Figure 4, more stocks are needed to get the desired level of diversification. One interpretation of the findings in this paper is that the recommended number of stocks in a buy-and-hold portfolio to attain on average (or with a particular degree of certainty) a reduction in diversifiable risk should not be based on results in periods when markets are in distress. Rather, as shown in Figure 4, during 2008-2010, US long term investors should instead conservatively rely on results obtained during normal financial market periods opting for larger portfolios (see also Table 3 Panel D).

Our results for other risk measures for $10 \%$ and $5 \%$ expected shortfall, lower partial moments (e.g., semi-variance) are very similar to the results when the risk measure used is standard deviation but are excluded from this paper for brevity's sake. ${ }^{24}$

${ }^{23}$ The OECD dated recessions (business cycle analysis database, http://stats.oecd.org) during the period of our study do not appear to have had an impact on the number of stocks needed for diversifying specific risk, unless these recessions coincide with financial market meltdowns.

${ }^{24}$ The results and figures are available from the authors upon request. 


\section{Conclusion}

In this study of five developed markets (the US, the UK, Japan, Canada and Australia) we analyse the required size of portfolios needed to achieve most diversification benefits. Using daily data, we trace the year-to-year dynamic of required portfolio sizes between 1975 and 2011. We compute several widely-accepted measures of risk: standard deviation, expected shortfall at $1 \%$, and terminal wealth standard deviation. This is the first empirical study to use an extreme risk measure to account for black swan events related to the recent Global Financial Crisis, as well as the more common asymmetries in returns during bull and bear markets. We find that investors concerned with extreme risk can achieve diversification benefits with a relatively small number of stocks.

We find that the correlation structures in the five markets change during periods of financial market distress. With the exception of the UK's financial market, we note that the downward trend in average correlations among stocks reported by Campbell et al. for the US between 1960 and 2000, reversed itself between 2000 and 2011, including the period 2002 to 2007 when the economy was not in crisis. Increased correlations among stocks after 2000, made portfolio diversification easier to achieve with a small number of stocks. Periods of market-wide crises and industry-specific meltdowns present different correlation structures. This has important implications for recommended portfolio sizes.

While the average all domestic US equity funds hold from 49 to 129 stocks, we find that these numbers are larger than the number of stocks required to assure $90 \%$ of the time a $90 \%$ reduction in diversifiable risk using both SD and ES. At the same time Ivkovic et al. (2008, Table 1, p.619) report that individual investors, as opposed to institutional investors in the US, hold between 3.9 and 11.7 stocks on average in their portfolios. We recommend that professional portfolio managers who use standard deviation as a measure of risk, and who seek to reduce $90 \%$ of diversifiable risk $90 \%$ percent of the time, instead of on average, should hold 49 stocks in the US; 43 in the UK; 39 in Japan; 40 in Canada; and 38 in Australia.

\section{Acknowledgments}

We would like to thank Russell Davidson, Mardi Dungey, Mike Hoy, Alex Maynard and Terry Walter for helpful comments and discussions. We appreciate the funding support of the Accounting and Finance Association of Australia and New Zealand. All errors and omissions are the sole responsibility of the authors.

\section{References}

Jan Annaert, Sofieke Van Osselaer, and Bert Verstraete. Performance evaluation of portfolio insurance strategies using stochastic dominance criteria. Journal of Banking \& Finance, $33(2): 272-280,2009$.

Philippe Artzner, Freddy Delbaen, Jean-Marc Eber, and David Heath. Thinking coherently. Risk, 10:68-71, 1997.

Kristine L. Beck, Sieven B. Perfect, and Pamela P. Peterson. The role of alternative methodology on the relation between portfolio size and diversification. Financial Review, 31(2): 381-406, 1996. 
Hicham Benjelloun. Evans and Archer - forty years later. Investment Management and Financial Innovations, , 7(1):98-104, 2010.

Ron Bird and Mark Tippett. Naive diversification and portfolio risk-a note. Management Science, 32(2):pp. 244-251, 1986.

Ted Bloomfield, Richard Leftwich, and John B. Long Jr. Portfolio strategies and performance. Journal of Financial Economics, 5(2):201 - 218, 1977.

Simone Brands and David R. Gallagher. Portfolio selection, diversification and fund-of-funds: a note. Accounting \& Finance, 45(2):185-197, 2005.

Peter Byrne and Stephen Lee. Risk reduction in the United Kingdom property market. Journal of Property Research, 17(1):23-46, 2000.

John Y. Campbell, Andrew W. Lo, and A. Craig MacKinlay. The Econometrics of Financial Markets. Princeton University Press, 1997.

John Y. Campbell, Martin Lettau, Burton G. Malkiel, and Yexiao Xu. Have individual stocks become more volatile? an empirical exploration of idiosyncratic risk. The Journal of Finance, 56(1):1-43, 2001.

David Copp and Sean Cleary. Diversification with Canadian stocks: how much is enough? Canadian Investment Review, 12(3):21-25, 1999.

Anthony C. Davison and Richard L. Smith. Models for exceedances over high thresholds. Journal of the Royal Statistical Society. Series B (Methodological), 52(3):pp. 393-442, 1990.

Wassim Dbouk and Lawrence Kryzanowski. Diversification benefits for bond portfolios. The European Journal of Finance, 15(5-6):533-553, 2009.

Dale L. Domian, David A. Louton, and Marie D. Racine. Diversification in portfolios of individual stocks: 100 stocks are not enough. Financial Review, 42(4):557-570, 2007.

Edwin J. Elton and Martin J. Gruber. Risk reduction and portfolio size: An analytical solution. The Journal of Business, 50(4):pp. 415-437, 1977.

John L. Evans and Stephen H. Archer. Diversification and the reduction of dispersion: An empirical analysis. The Journal of Finance, 23(5):pp. 761-767, 1968.

Eugene F. Fama. Market efficiency, long-term returns, and behavioral finance. Journal of Financial Economics, 49(3):283 - 306, 1998.

Bruce D. Fielitz. Indirect versus direct diversification. Financial Management, 3(4):pp. 54-62, 1974.

Lawrence Fisher and James H. Lorie. Some studies of variability of returns on investments in common stocks. The Journal of Business, 43(2):pp. 99-134, 1970. 
Kenneth R. French, G.William Schwert, and Robert F. Stambaugh. Expected stock returns and volatility. Journal of Financial Economics, 19(1):3 - 29, 1987.

Lawrence R Glosten, Ravi Jagannathan, and David E Runkle. On the relation between the expected value and the volatility of the nominal excess return on stocks. Journal of Finance, 48(5):1779-1801, December 1993.

William N. Goetzmann and Alok Kumar. Equity portfolio diversification. Review of Finance, 12(3):433-463, 2008.

Namwon Hyung and Casper G. de Vries. Portfolio diversification effects of downside risk. Journal of Financial Econometrics, 3(1):107-125, 2005.

Namwon Hyung and Casper G. de Vries. Simulating and calibrating diversification against black swans. Journal of Economic Dynamics \&5 Control, 36:1162-1175, 2012.

Rustam Ibragimov and Johan Walden. The limits of diversification when losses may be large. Journal of Banking \& Finance, 31(8):2551 - 2569, 2007.

Zoran Ivkovic, Clemens Sialm, and Scott Weisbenner. Portfolio concentration and the performance of individual investors. Journal of Financial and Quantitative Analysis, 43: 613-655, 92008.

Edward H. Jennings. An empirical analysis of some aspects of common stock diversification. Journal of Financial and Quantitative Analysis, 6(02):797-813, 1971.

Keith H. Johnson and Donald S. Shannon. A note on diversification and the reduction of dispersion. Journal of Financial Economics, 1(4):365 - 372, 1974.

Robert C. Klemkosky and John D. Martin. The effect of market risk on portfolio diversification. The Journal of Finance, 30(1):pp. 147-154, 1975.

Lawrence Kryzanowski and Singh Singh. Should minimum portfolio sizes be prescribed for achieving sufficiently well-diversified equity portfolios? Frontiers in Finance and Economics, 7(2):1-37, 2010.

Henry A. Latane and William E. Young. Test of portfolio building rules. Journal of Finance, 24(4):595 - 612, 1969.

Edward S. O'Neal. How many mutual funds constitute a diversified mutual fund portfolio? Financial Analysts Journal, 53(2):pp. 37-46, 1997.

James III Pickands. Statistical inference using extreme order statistics. The Annals of Statistics, 3(1):pp. 119-131, 1975.

Carmen M. Reinhart and Kenneth Rogoff. This Time Is Different: Eight Centuries of Financial Folly. Princeton University Press, 2009.

Bruno H. Solnik. Why not diversify internationally rather than domestically? Financial Analysts Journal, 30(4):pp. 48-52+54, 1974. 
Meir Statman. How many stocks make a diversified portfolio? The Journal of Financial and Quantitative Analysis, 22(3):pp. 353-363, 1987.

Giorgio Szego. Measures of risk. Journal of Banking and Finance, 26(7):1253 - 1272, 2002.

Gordon Y.N. Tang. How efficient is naive portfolio diversification? an educational note. Omega, 32(2):155 - 160, 2004.

Thomas M. Tole. You can't diversify without diversifying. Journal of Portfolio Management, 8:5-11, 1982.

Wayne H. Wagner and Sheila C. Lau. The effect of diversification on risk. Financial Analysts Journal, 27(6):pp. 48-53, 1971. 


\begin{tabular}{|c|c|c|c|c|c|c|c|c|c|c|c|c|c|c|c|}
\hline & \multicolumn{3}{|c|}{ United States } & \multicolumn{3}{|c|}{ United Kingdom } & \multicolumn{3}{|c|}{ Japan } & \multicolumn{3}{|c|}{ Canada } & \multicolumn{3}{|c|}{ Australia } \\
\hline & $1(1 a)$ & $2(2 a)$ & 3 & $4(4 a)$ & $5(5 a)$ & 6 & $7(7 a)$ & $8(8 a)$ & 9 & $10(10 a)$ & $11(11 a)$ & 12 & $13(13 a)$ & $14(14 a)$ & 15 \\
\hline Year & SD & ES & TWSD & SD & ES & TWSD & SD & ES & TWSD & SD & ES & TWSD & SD & ES & TWSD \\
\hline 1975 & $19(40)$ & $14(33)$ & 83 & $19(47)$ & $12(31)$ & 92 & $20(39)$ & $11(39)$ & 83 & $12(20)$ & $11(19)$ & 23 & $22(32)$ & $16(31)$ & 54 \\
\hline 1976 & $21(42)$ & $19(42)$ & 88 & $19(49)$ & $16(33)$ & 95 & $21(36)$ & $14(43)$ & 85 & $15(22)$ & $19(24)$ & 29 & $22(33)$ & $17(31)$ & 54 \\
\hline 1977 & $23(45)$ & $19(55)$ & 89 & $19(51)$ & $15(40)$ & 95 & $22(34)$ & $14(26)$ & 84 & $18(24)$ & $19(28)$ & 31 & $24(31)$ & $21(28)$ & 54 \\
\hline 1978 & $23(45)$ & $17(63)$ & 88 & $26(47)$ & $15(39)$ & 92 & $24(35)$ & $15(27)$ & 82 & $18(23)$ & $16(25)$ & 34 & $25(31)$ & $20(26)$ & 53 \\
\hline 1979 & $20(42)$ & $13(50)$ & 89 & $26(44)$ & $20(35)$ & 87 & $24(35)$ & $15(28)$ & 89 & $19(32)$ & $14(36)$ & 44 & $27(34)$ & $21(29)$ & 54 \\
\hline 1980 & $20(45)$ & $14(64)$ & 92 & $27(46)$ & $20(38)$ & 91 & $27(38)$ & $14(27)$ & 90 & $17(36)$ & $14(52)$ & 49 & $25(34)$ & $19(28)$ & 56 \\
\hline 1981 & $19(42)$ & $14(61)$ & 93 & $25(47)$ & $14(37)$ & 93 & $26(38)$ & $16(31)$ & 83 & $17(38)$ & $13(50)$ & 51 & $23(34)$ & $18(28)$ & 56 \\
\hline 1982 & $19(41)$ & $13(49)$ & 91 & $26(52)$ & $18(52)$ & 92 & $26(39)$ & $15(27)$ & 88 & $17(37)$ & $14(50)$ & 54 & $23(36)$ & $19(28)$ & 57 \\
\hline 1983 & $20(42)$ & $13(34)$ & 91 & $29(55)$ & $18(60)$ & 86 & $26(38)$ & $16(29)$ & 88 & $18(35)$ & $14(33)$ & 49 & $22(34)$ & $18(28)$ & 54 \\
\hline 1984 & $20(39)$ & $17(35)$ & 94 & $36(66)$ & $23(51)$ & 92 & $26(38)$ & $13(24)$ & 91 & $24(40)$ & $22(54)$ & 48 & $21(33)$ & $20(28)$ & 54 \\
\hline 1985 & $21(41)$ & $19(39)$ & 85 & $32(46)$ & $19(39)$ & 85 & $27(37)$ & $12(23)$ & 84 & $21(31)$ & $24(41)$ & 43 & $22(32)$ & $19(30)$ & 54 \\
\hline 1986 & $22(42)$ & $19(48)$ & 91 & $30(46)$ & $21(40)$ & 91 & $25(32)$ & $14(26)$ & 89 & $25(36)$ & $31(45)$ & 41 & $22(32)$ & $17(27)$ & 54 \\
\hline 1987 & $17(48)$ & $10(111)$ & 86 & $20(48)$ & $12(105)$ & 88 & $18(27)$ & $10(31)$ & 88 & $22(42)$ & $22(64)$ & 49 & $18(39)$ & $13(45)$ & 57 \\
\hline 1988 & $18(49)$ & $10(109)$ & 91 & $18(51)$ & $10(129)$ & 89 & $18(28)$ & $10(33)$ & 87 & $22(40)$ & $21(58)$ & 44 & $16(38)$ & $14(45)$ & 52 \\
\hline 1989 & $16(51)$ & $9(113)$ & 91 & $14(47)$ & $9(127)$ & 74 & $17(26)$ & $9(39)$ & 90 & $18(31)$ & $15(37)$ & 40 & $14(37)$ & $10(44)$ & 49 \\
\hline 1990 & $21(44)$ & $14(49)$ & 90 & $17(32)$ & $11(38)$ & 63 & $15(30)$ & $15(84)$ & 88 & $18(26)$ & $15(24)$ & 33 & $21(34)$ & $28(45)$ & 43 \\
\hline 1991 & $26(57)$ & $21(55)$ & 89 & $16(38)$ & $12(33)$ & 66 & $15(35)$ & $12(65)$ & 93 & $22(33)$ & $19(33)$ & 43 & $25(43)$ & $28(51)$ & 55 \\
\hline 1992 & $24(42)$ & $16(41)$ & 95 & $17(40)$ & $13(27)$ & 63 & $14(38)$ & $13(52)$ & 89 & $26(34)$ & $22(32)$ & 47 & $25(40)$ & $26(47)$ & 57 \\
\hline 1993 & $26(43)$ & $16(40)$ & 94 & $17(37)$ & $14(32)$ & 64 & $15(37)$ & $13(45)$ & 87 & $30(43)$ & $27(41)$ & 54 & $26(38)$ & $25(48)$ & 60 \\
\hline 1994 & $29(43)$ & $19(38)$ & 96 & $16(35)$ & $14(33)$ & 65 & $15(39)$ & $12(45)$ & 90 & $34(45)$ & $22(34)$ & 64 & $26(38)$ & $27(49)$ & 62 \\
\hline 1995 & $31(46)$ & $17(33)$ & 96 & $18(29)$ & $14(27)$ & 65 & $16(36)$ & $10(43)$ & 92 & $36(44)$ & $22(31)$ & 72 & $25(36)$ & $18(33)$ & 62 \\
\hline 1996 & $30(47)$ & $17(34)$ & 94 & $22(49)$ & $21(41)$ & 65 & $17(35)$ & $11(41)$ & 90 & $39(51)$ & $27(53)$ & 76 & $24(37)$ & $15(26)$ & 68 \\
\hline 1997 & $29(46)$ & $17(37)$ & 95 & $18(31)$ & $12(28)$ & 65 & $18(43)$ & $16(66)$ & 93 & $37(49)$ & $21(38)$ & 80 & $22(38)$ & $13(34)$ & 69 \\
\hline 1998 & $26(45)$ & $15(45)$ & 89 & $19(35)$ & $17(41)$ & 64 & $17(50)$ & $14(69)$ & 91 & $36(50)$ & $21(40)$ & 82 & $22(40)$ & $17(43)$ & 69 \\
\hline 1999 & $28(45)$ & $14(33)$ & 99 & $19(33)$ & $15(36)$ & 70 & $18(44)$ & $13(50)$ & 86 & $37(49)$ & $20(34)$ & 84 & $23(40)$ & $14(40)$ & 74 \\
\hline 2000 & $28(50)$ & $16(35)$ & 97 & $20(37)$ & $16(33)$ & 66 & $19(36)$ & $17(48)$ & 89 & $37(49)$ & $22(37)$ & 86 & $28(42)$ & $18(37)$ & 71 \\
\hline 2001 & $27(56)$ & $19(42)$ & 93 & $20(49)$ & $16(42)$ & 73 & $20(34)$ & $19(55)$ & 89 & $35(51)$ & $22(45)$ & 85 & $29(52)$ & $18(52)$ & 77 \\
\hline 2002 & $25(60)$ & $18(41)$ & 94 & $21(46)$ & $16(32)$ & 73 & $18(36)$ & $14(47)$ & 90 & $31(51)$ & $21(42)$ & 79 & $27(47)$ & $20(56)$ & 77 \\
\hline 2003 & $25(59)$ & $19(42)$ & 98 & $19(46)$ & $17(36)$ & 71 & $18(41)$ & $13(50)$ & 97 & $33(49)$ & $23(41)$ & 82 & $27(42)$ & $18(39)$ & 75 \\
\hline 2004 & $25(55)$ & $24(52)$ & 99 & $19(44)$ & $17(34)$ & 75 & $18(43)$ & $11(78)$ & 92 & $36(52)$ & $26(50)$ & 80 & $30(44)$ & $21(34)$ & 72 \\
\hline 2005 & $26(50)$ & $24(41)$ & 94 & $20(40)$ & $19(38)$ & 77 & $19(44)$ & $9(90)$ & 88 & $33(51)$ & $23(43)$ & 85 & $30(41)$ & $17(28)$ & 76 \\
\hline 2006 & $26(48)$ & $23(42)$ & 97 & $22(36)$ & $14(35)$ & 77 & $17(47)$ & $7(112)$ & 95 & $29(46)$ & $18(42)$ & 81 & $28(44)$ & $15(30)$ & 80 \\
\hline 2007 & $24(45)$ & $17(35)$ & 93 & $20(37)$ & $17(35)$ & 86 & $17(48)$ & $8(64)$ & 92 & $26(50)$ & $16(40)$ & 84 & $26(44)$ & $15(39)$ & 84 \\
\hline 2008 & $16(56)$ & $10(71)$ & 93 & $19(43)$ & $16(43)$ & 83 & $16(53)$ & $15(67)$ & 93 & $21(48)$ & $16(55)$ & 86 & $20(44)$ & $17(54)$ & 82 \\
\hline 2009 & $17(67)$ & $13(72)$ & 92 & $19(42)$ & $15(45)$ & 83 & $17(53)$ & $11(64)$ & 92 & $20(46)$ & $14(48)$ & 79 & $20(41)$ & $14(54)$ & 84 \\
\hline 2010 & $18(68)$ & $14(72)$ & 96 & $19(46)$ & $15(44)$ & 86 & $17(50)$ & $10(63)$ & 89 & $19(47)$ & $14(50)$ & 86 & $20(44)$ & $15(49)$ & 80 \\
\hline 2011 & $18(73)$ & $14(63)$ & 94 & $21(40)$ & $17(33)$ & 85 & $17(53)$ & $15(92)$ & 97 & $22(46)$ & $16(36)$ & 87 & $21(43)$ & $17(40)$ & 81 \\
\hline Average & $23(49)$ & $16(52)$ & 92 & $21(43)$ & $16(44)$ & 79 & 19 (39) & $13(50)$ & 89 & $25(40)$ & $19(41)$ & 61 & $24(38)$ & $18(38)$ & 64 \\
\hline
\end{tabular}

Table 1: Recommended portfolio size to achieve $\mathbf{9 0 \%}$ reduction in diversifiable risk. The table presents the average number of stocks and the 90th percentile of number of stocks (in parenthesis) based on SD, ES at the 1\% level and TWSD as risk measures. 


\begin{tabular}{|c|c|c|c|c|c|c|c|c|c|c|}
\hline \multirow{2}{*}{ Event } & \multicolumn{2}{|c|}{$\overline{\text { US }}$} & \multicolumn{2}{|c|}{ UK } & \multicolumn{2}{|c|}{ Japan } & \multicolumn{2}{|c|}{ Canada } & \multicolumn{2}{|c|}{ Australia } \\
\hline & SD & $E S_{1 \%}$ & SD & $E S_{1 \%}$ & SD & $E S_{1 \%}$ & SD & $E S_{1 \%}$ & SD & $E S_{1 \%}$ \\
\hline $\begin{array}{l}\text { The } 1973 \text { oil crisis } \\
(1973-1974)\end{array}$ & & & & & & & & & & \\
\hline $\begin{array}{l}\text { Bear market of } \\
1977-1978\end{array}$ & $23(45)$ & $\begin{array}{c}17-19 \\
(55-63)\end{array}$ & & & & & & & & \\
\hline $\begin{array}{l}\text { The } 1979 \text { (or second) oil } \\
\text { crisis (1979-1982) }\end{array}$ & $\begin{array}{c}19-20 \\
(41-45)\end{array}$ & $\begin{array}{c}13-14 \\
(49-64)\end{array}$ & & & & & $\begin{array}{c}17-19 \\
(32-38)\end{array}$ & $\begin{array}{c}13-14 \\
(36-52)\end{array}$ & & \\
\hline $\begin{array}{l}\text { Bear market of } \\
1981-1982\end{array}$ & & & & & & & & & $23(34-36)$ & $18-19(28)$ \\
\hline Black Monday (1987) & $17(48)$ & $10(111)$ & $20(48)$ & $12(105)$ & $18(27)$ & $10(31)$ & $22(42)$ & $22(64)$ & $18(39)$ & $13(45)$ \\
\hline $\begin{array}{l}\text { Friday the 13th } \\
\text { mini-crash (1989) }\end{array}$ & $16(51)$ & $9(113)$ & & & & & & & & \\
\hline $\begin{array}{l}\text { First Gulf War } \\
(1990-1991)\end{array}$ & $\begin{array}{c}21-26 \\
(44-57)\end{array}$ & $\begin{array}{c}14-21 \\
(49-55)\end{array}$ & & & $15(30-35)$ & $\begin{array}{c}12-15 \\
(65-84)\end{array}$ & & & $\begin{array}{c}21-25 \\
(34-33)\end{array}$ & $28(45-51)$ \\
\hline $\begin{array}{l}\text { Japanese Asset Price } \\
\text { bubble (1990-1992) }\end{array}$ & & & & & $\begin{array}{c}14-15 \\
(30-38)\end{array}$ & $\begin{array}{c}12-15 \\
(52-84)\end{array}$ & & & & \\
\hline Black Wednesday (1992) & & & $17(40)$ & $13(27)$ & & & & & & \\
\hline $\begin{array}{l}\text { Bear market of } \\
1996-1998\end{array}$ & & & & & $\begin{array}{c}17-18 \\
(35-50)\end{array}$ & $\begin{array}{c}11-16 \\
(41-69)\end{array}$ & & & & \\
\hline $\begin{array}{l}\text { Asian Financial Crisis } \\
(1997)\end{array}$ & & & & & $18(43)$ & $16(66)$ & & & $22(38)$ & $13(34)$ \\
\hline Collapse of LTCM (1998) & $26(45)$ & $15(45)$ & $19(35)$ & $17(31)$ & $17(50)$ & $14(69)$ & $36(50)$ & $21(40)$ & $22(40)$ & $17(43)$ \\
\hline $\begin{array}{l}\text { Dot-com bubble } \\
(2000-2002)\end{array}$ & $\begin{array}{l}25-28 \\
(50-60)\end{array}$ & $\begin{array}{c}16-19 \\
(35-42)\end{array}$ & $\begin{array}{c}20-21 \\
(37-49)\end{array}$ & $16(32-42)$ & $\begin{array}{c}18-20 \\
(34-36)\end{array}$ & $\begin{array}{c}14-19 \\
(47-55)\end{array}$ & $\begin{array}{c}31-37 \\
(49-51)\end{array}$ & $\begin{array}{c}21-22 \\
(42-45)\end{array}$ & $\begin{array}{c}27-29 \\
(42-52)\end{array}$ & $\begin{array}{c}18-20 \\
(37-56)\end{array}$ \\
\hline $\begin{array}{l}\text { Global Financial Crisis } \\
(2008)\end{array}$ & $16(56)$ & $10(71)$ & $19(43)$ & $16(43)$ & $16(53)$ & $15(67)$ & $21(48)$ & $16(55)$ & $20(44)$ & $17(54)$ \\
\hline
\end{tabular}

Table 2: Dates for crises, stock market crashes and their aftermath. Source: Symbol $\checkmark$ refers to events identified in Reinhart and Rogoff (2009) and Dates for Banking Crises, Currency Crashes, Sovereign Domestic or External Default, Inflation Crises, and Stock Market Crashes webpage on the authors website: http://www.reinhartandrogoff.com/data/. The symbol + refers to events we include in addition to those identified in Reinhart and Rogoff (2009): for all five countries in our sample - Black Monday (1987), and the collapse of Long Term Capital Management (LTCM) in 1998; for the UK - Black Wednesday (1992) ; for Australia - the 1973 oil crisis (1973-1974), the Asian Financial Crisis (1997) and the Dot-com bubble (2000-2002); for Canada - the 1979 oil crisis (1979-1982). The numbers in the SD and $E S_{1 \%}$ columns represent the range of the number of stocks required to reduce diversifiable risk by $90 \%$ (with $90 \%$ certainty). 


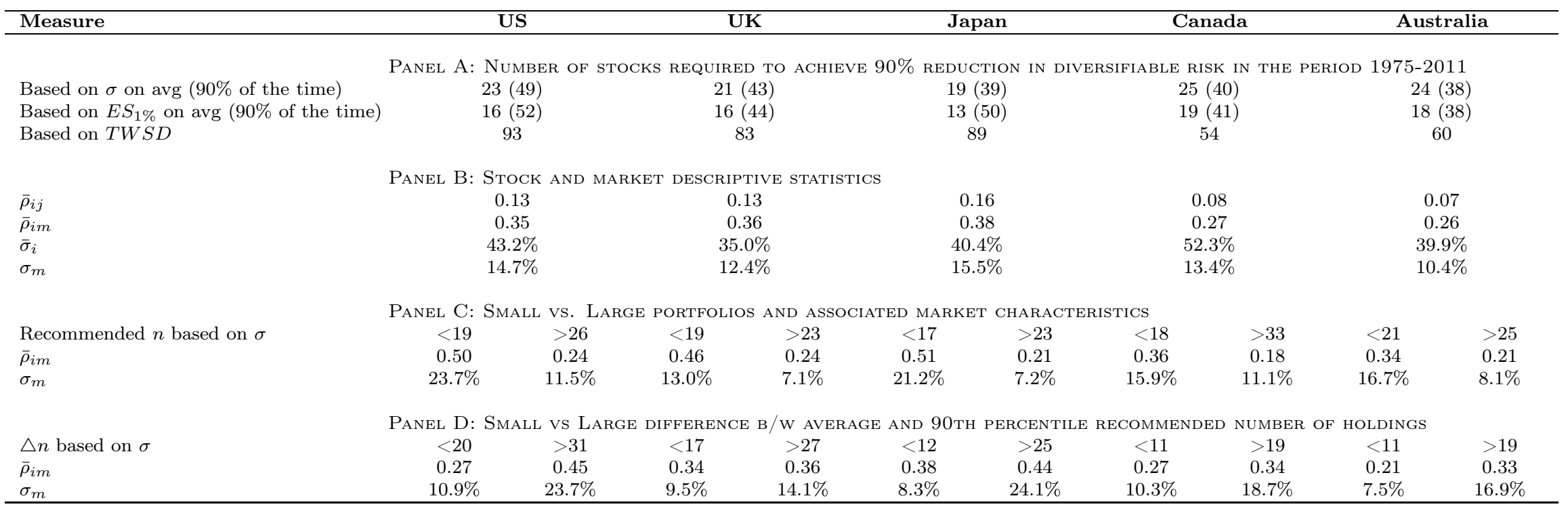

Table 3: Portfolio size results. Panel A provides the average number of stocks required to diversify on average (and $90 \%$ of the time) $90 \%$ of diversifiable risk between 1975 and 2011 using the three risk measures. PANEL B details average correlations among individual stocks $\left(\bar{\rho}_{i j}\right)$, average correlations of stocks with the market $\left(\bar{\rho}_{i m}\right)$, average security standard deviations $\left(\bar{\sigma}_{i}\right)$ and market volatility $\left(\sigma_{m}\right)$. PANEL C relates recommended number of stocks with market characteristics. We identify years with the largest recommended portfolio sizes (top 3rd of the sample) and estimate $\bar{\rho}_{i m}$ and $\sigma_{m}$ for these years only. We then identify years with the lowest recommended portfolio sizes (bottom 3rd of the sample) and estimate $\bar{\rho}_{i m}$ and $\sigma_{m}$ for these years only. PANeL D is constructed similarly to PANel $\mathbf{C}$ but relies on the difference between the number of stocks required to assure the investor of the desired level of diversification $90 \%$ of the time and the portfolio size of the average investor (the difference between the dashed and solid lines in Figures 4, 6, 8, 10 and 12). 


\section{Online Appendix only}

The following pages are intended as a supplement to the main manuscript. The following pages, figures and tables therein are not referenced in the main manuscript.

In Table 4, we present a detailed summary of the literature.

It is also convenient to represent an alternative standardization such as the the one below:

$$
\eta_{4}(n)=\frac{\overline{\Omega^{n}}}{\Omega^{N}} .
$$

When $n=1$, the measure shows how many times the average security risk is higher than market risk. As the number of stocks in the portfolio increases, the measure approaches 1 from above. Since the market risk level changes from year to year, we pick this particular measure to facilitate our visual analysis. We depict this measure in panels (A) and (B) of Figures 13, 14, 15, 16 and 17.

The vertical axis in Figure 13.A shows the average level of standard deviation normalized by the market standard deviation as defined by equation (12) above. For each year from 1975 to 2011, we construct an asymptote and show the average $n$-stock portfolio standard deviation for $n=1 . .20$ relative to the market standard deviation for each year. We observe in Figure 13.A that the average security risk, measured by standard deviation, was at its highest from 1994 to 1996, amounting to five times greater than the market standard deviation.

Figure 18 depicts recommended portfolio size (color bar) by the level of diversification (vertical axis) across time (horizontal axis). 


\section{Literature Summary}

Table 4. The summary of studies listed chronologically in the first column outlines the period of the study (column 2), the data frequency used (column 3) and the market analysed (column 4). Column 5 lists measures used for (i) risk, (ii) performance, and (iii) diversification. Stock sample figures (in column 6) represent the sample size of (or the universe of investable) common stocks in the period considered, unless stated otherwise. Column 7 represents the maximum size of a portfolio (in terms of the number of stocks used to construct random portfolio). For most of the studies, the market portfolio proxy is constructed based on equal weighting of all securities available in the market, unless specifically stated otherwise in column 8. We also note down, in column 9 , the number of simulations, $M$, used to derive the central tendency of a risk measure of each $n$-stock portfolio. Column 10 provides the recommendation on the portfolio size required to achieve a specified level/percentage of diversification in parentheses. Column 11 indicates the sampling procedure used to construct random portfolios.

\begin{tabular}{|c|c|c|c|c|c|c|c|c|c|c|}
\hline Study & Period & Freq. & Market & Measures & Sample & $\begin{array}{l}\text { Max } \\
\text { size }\end{array}$ & $\begin{array}{l}\text { Market } \\
\text { proxy }\end{array}$ & $M$ & $\begin{array}{l}\text { No. of stocks } \\
\text { (diversif.\%) }\end{array}$ & Sampling \\
\hline (1) & (2) & (3) & (4) & (5) & (6) & (7) & (8) & (9) & (10) & (11) \\
\hline $\begin{array}{l}\text { Evans and } \\
\text { Archer (1968) }\end{array}$ & $\begin{array}{l}1958-1967 \\
\end{array}$ & $\begin{array}{l}\text { semi- } \\
\text { annual }\end{array}$ & US & SD & 470 & 40 & & 60 & $8-10$ & uniform \\
\hline $\begin{array}{l}\text { Fisher and } \\
\text { Lorie (1970) }\end{array}$ & 1926-1965 & annual & US & $\begin{array}{l}\text { wealth ratios: SD, } \\
\text { MAD, mean } \\
\text { difference, Gini's } \\
\text { mean difference, } \\
\text { coefficient of } \\
\text { concentration }\end{array}$ & & 128 & & & $\begin{array}{l}8-16(85 \%), \\
16-32(90 \%), \\
128(99 \%)\end{array}$ & $\begin{array}{l}\text { stratified } \\
\text { sampling } \\
\text { (industry) }\end{array}$ \\
\hline $\begin{array}{l}\text { Jennings } \\
(1971)\end{array}$ & 1955-1965 & annual & US & $\begin{array}{l}\text { probability of loss, } \\
\text { terminal wealth }\end{array}$ & $\begin{array}{l}\text { all listed NYSE } \\
\text { stocks }(\approx 1715)\end{array}$ & & $\begin{array}{l}\text { full sample, } \\
\text { equally } \\
\text { weighted }\end{array}$ & & 15 & uniform \\
\hline $\begin{array}{l}\text { Wagner and } \\
\text { Lau (1971) }\end{array}$ & 1960-1970 & monthly & US & $\mathrm{SD}, \beta, R^{2}$ & $\begin{array}{l}\text { all listed NYSE } \\
\text { stocks }\end{array}$ & 200 & $\begin{array}{l}\text { full sample, } \\
\text { equally } \\
\text { weighted }\end{array}$ & 10 & 20 & $\begin{array}{l}\text { uniform, } \\
\text { classified } \\
\text { (low risk } \\
\text { vs. high } \\
\text { risk) }\end{array}$ \\
\hline Fielitz (1974) & 1964-1968 & quarterly & US & $\begin{array}{l}\text { MAD, Sharpe, } \\
\text { Treynor }\end{array}$ & 200 & 20 & $\begin{array}{l}\text { full sample, } \\
\text { equally } \\
\text { weighted }\end{array}$ & 40 & 8 & uniform \\
\hline
\end{tabular}




\begin{tabular}{|c|c|c|c|c|c|c|c|c|c|c|}
\hline Study & Period & Freq. & Market & Measures & Sample & $\begin{array}{l}\text { Max } \\
\text { size }\end{array}$ & $\begin{array}{l}\text { Market } \\
\text { proxy }\end{array}$ & $M$ & $\begin{array}{l}\text { No. of stocks } \\
\text { (diversif.\%) }\end{array}$ & Sampling \\
\hline & $(2)$ & (3) & (4) & (5) & (6) & (7) & (8) & (9) & $(10)$ & (11) \\
\hline $\begin{array}{l}\text { Johnson and } \\
\text { Shannon } \\
(1974)\end{array}$ & 1965-1972 & quarterly & US & variance & 50 & 17 & & 20 & $3-7$ & $\begin{array}{l}\text { quadratic } \\
\text { optimiza- } \\
\text { tion }\end{array}$ \\
\hline Solnik (1974) & 1966-1971 & weekly & $\begin{array}{l}\text { US, UK, } \\
\text { DE, FR, } \\
\text { CH, IT, } \\
\text { BE, NL }\end{array}$ & $\mathrm{SD}$ & $\begin{array}{l}\text { all listed on } \\
\text { NYSE, AMEX } \\
+300 \text { European } \\
\text { stocks }\end{array}$ & 300 & & 60 & $10-15$ & uniform \\
\hline $\begin{array}{l}\text { Klemkosky } \\
\text { and Martin } \\
(1975)\end{array}$ & $1963-1973$ & monthly & US & $\begin{array}{l}\text { residual variance, } \\
\text { residual variance } \\
\text { of low vs. high } \\
\text { beta portfolios }\end{array}$ & 350 & 25 & S\&P500 & $350 /($ & $3-17$ & uniform \\
\hline $\begin{array}{l}\text { Elton and } \\
\text { Gruber } \\
(1977)\end{array}$ & analytical & - & - & variance & & & & & 20 & uniform \\
\hline $\begin{array}{l}\text { Bloomfield et } \\
\text { al (1977) }\end{array}$ & 1953-1970 & monthly & US & $\mathrm{SD}$ & $\begin{array}{l}823-893,3 \\
\text { subperiods }\end{array}$ & 50 & $?$ & 20 & $?$ & $\begin{array}{l}\text { uniform, } \\
\text { quadratic } \\
\text { optimiza- } \\
\text { tion }\end{array}$ \\
\hline $\begin{array}{l}\text { Bird and } \\
\text { Tippett } \\
\text { (1986) }\end{array}$ & $1958-1973$ & monthly & AUS & $\mathrm{SD}$ & 188 & 25 & $\begin{array}{l}\text { full sample, } \\
\text { equally } \\
\text { weighted }\end{array}$ & 40 & $10-15$ & uniform \\
\hline $\begin{array}{l}\text { Statman } \\
(1987)\end{array}$ & 1926-1984 & $?$ & US & $\mathrm{SD}$ & US & & S\&P500 & & $30-40$ & uniform \\
\hline $\begin{array}{l}\text { Beck et al. } \\
(1996)\end{array}$ & $1982-1991$ & monthly & US & $\begin{array}{l}\text { variances, } \\
\text { correlations, } \\
\text { variance ratios }\end{array}$ & $\begin{array}{l}\text { all listed on } \\
\text { NYSE, AMEX } \\
(1221)\end{array}$ & 70 & $\begin{array}{l}\text { full sample, } \\
\text { equally } \\
\text { weighted }\end{array}$ & $\begin{array}{l}50 \\
100 \\
200 \\
500 \\
1000 \\
2000\end{array}$ & $14-20$ & uniform \\
\hline $\begin{array}{l}\text { O'Neal } \\
\text { (1997) }\end{array}$ & 1976-1994 & quarterly & US & $\begin{array}{l}\text { TWSD and SD, } \\
\text { mean shortfall, } \\
\text { semi-variance }\end{array}$ & $\begin{array}{l}103 \text { growth and } 65 \\
\text { growth and } \\
\text { income funds }\end{array}$ & 30 & & 1000 & 16-18 FoF & uniform \\
\hline
\end{tabular}




\begin{tabular}{|c|c|c|c|c|c|c|c|c|c|c|}
\hline $\begin{array}{r}\text { Study } \\
(1)\end{array}$ & $\begin{array}{r}\text { Period } \\
\text { (2) }\end{array}$ & $\begin{array}{r}\text { Freq. } \\
(3)\end{array}$ & $\begin{array}{c}\text { Market } \\
\text { (4) }\end{array}$ & $\begin{array}{r}\text { Measures } \\
\text { (5) }\end{array}$ & Sample & $\begin{array}{l}\text { Max } \\
\text { size } \\
\\
(7)\end{array}$ & $\begin{array}{l}\text { Market } \\
\text { proxy } \\
\\
(8)\end{array}$ & $\begin{array}{l}M \\
\text { (9) }\end{array}$ & $\begin{array}{l}\text { No. of stocks } \\
\text { (diversif.\%) } \\
\text { (10) }\end{array}$ & $\begin{array}{c}\text { Sampling } \\
\text { (11) }\end{array}$ \\
\hline $\begin{array}{l}\text { Copp and } \\
\text { Cleary (1999) }\end{array}$ & 1985-1997 & monthly & CAN & variance & 222 and 236 & 200 & $\begin{array}{l}\text { full sample, } \\
\text { equally } \\
\text { weighted }\end{array}$ & 5000 & $\begin{array}{l}10(68 \%), 20 \\
(78 \%), 30 \\
(84 \%), 50 \\
(90 \%), 90 \\
(99.6 \%)\end{array}$ & uniform \\
\hline $\begin{array}{l}\text { Byrne and } \\
\text { Lee }(2000)\end{array}$ & & & UK & & & & & & real estate & \\
\hline Tang (2004) & analytical & - & - & variance & & & & & $\begin{array}{l}10(90 \%), 20 \\
(95 \%), 90(99 \%)\end{array}$ & uniform \\
\hline $\begin{array}{l}\text { Brands and } \\
\text { Gallagher } \\
(2005)\end{array}$ & 1989-1999 & monthly & AUS & $\begin{array}{l}\text { SD, TWSD, } \\
\text { Sharpe, Skew, } \\
\text { Kurtosis }\end{array}$ & $\begin{array}{l}134 \text { open-end } \\
\text { equity funds }\end{array}$ & 30 & $\begin{array}{l}\text { full sample, } \\
\text { equally } \\
\text { weighted }\end{array}$ & 10000 & 6 & uniform \\
\hline $\begin{array}{l}\text { Domian et al. } \\
(2007)\end{array}$ & $1985-2004$ & $\begin{array}{l}\text { daily } \\
\text { (indi- } \\
\text { rectly) }\end{array}$ & US & $\begin{array}{l}\text { TW, safety first } \\
\text { criterion }\end{array}$ & $\begin{array}{l}1000 \text { largest } \\
\text { common stock } \\
\text { series from NYSE, } \\
\text { NASDAQ, AMEX } \\
\text { with preference for } \\
\text { large cap }\end{array}$ & 200 & $\begin{array}{l}\text { full sample, } \\
\text { equally } \\
\text { weighted }\end{array}$ & & 164 & $\begin{array}{l}\text { uniform, } \\
\text { industry }\end{array}$ \\
\hline $\begin{array}{l}\text { Goetzmann } \\
\text { and Kumar } \\
(2008)\end{array}$ & 1991-1996 & monthly & & $\begin{array}{l}\mathrm{NV} \text {, sum of } \\
\text { squared stocks } \\
\text { weights in a } \\
\text { portfolio, num. of } \\
\text { stocks }\end{array}$ & & & $\begin{array}{l}\text { S\&P500 and } \\
\text { full sample } \\
\text { equally } \\
\text { weighted }\end{array}$ & & & \\
\hline $\begin{array}{l}\text { Dbouk and } \\
\text { Kryzanowski } \\
(2009)\end{array}$ & 1985-1997 & monthly & US & $\begin{array}{l}\text { correlation of } \\
\text { bond returns, } \\
\text { excess standard } \\
\text { and mean derived } \\
\text { deviation, Sortino, } \\
\text { skew, kurtosis }\end{array}$ & $\begin{array}{l}\text { bonds from } \\
\text { Lehman Brothers } \\
\text { Fixed Income } \\
\text { Database (total } \\
27,497 \text { bonds) }\end{array}$ & & & & $\begin{array}{l}\text { bond portfolios } \\
\text { of } 25-40 \text { bonds }\end{array}$ & \\
\hline $\begin{array}{l}\text { Benjelloun } \\
(2010)\end{array}$ & $1980-2000$ & monthly & US & TWSD, SD & all listed on CRSP & 100 & $\begin{array}{l}\text { estimated } \\
\text { asymptote } \\
\text { from regression }\end{array}$ & 10000 & $40-50$ & $\begin{array}{l}\text { uniform } \\
\text { and market } \\
\text { weights }\end{array}$ \\
\hline
\end{tabular}




\begin{tabular}{|c|c|c|c|c|c|c|c|c|c|c|}
\hline (1) & $\begin{array}{r}\text { Period } \\
\text { (2) }\end{array}$ & $\begin{array}{r}\text { Freq. } \\
(3)\end{array}$ & Market & $\begin{array}{r}\text { Measures } \\
\text { (5) }\end{array}$ & Sample & $\begin{array}{l}\text { Max } \\
\text { size } \\
\\
(7)\end{array}$ & $\begin{array}{l}\text { Market } \\
\text { proxy } \\
\\
(8)\end{array}$ & M & $\begin{array}{l}\text { No. of stocks } \\
\text { (diversif.\%) } \\
\\
(10)\end{array}$ & $\begin{array}{c}\text { Sampling } \\
\text { (11) }\end{array}$ \\
\hline $\begin{array}{l}\text { Kryzanowski } \\
\text { and Singh } \\
(2010)\end{array}$ & $1975-2003$ & monthly & CAN & $\begin{array}{l}\text { correlation, } \\
\text { cross-sectional and } \\
\text { time-series (semi) } \\
\text { variation, MDD, } \\
\text { MRD, NV }\end{array}$ & $\begin{array}{l}\text { listed on TSX, } \\
\text { cross-listed on } \\
\text { TSX/US, small vs. } \\
\text { Big, IT firms }\end{array}$ & 100 & $\begin{array}{l}\text { several } \\
\text { samples, all } \\
\text { equally } \\
\text { weighted }\end{array}$ & 5000 & $\begin{array}{l}20-25(90 \%) \\
\text { corr., 40-45 } \\
(90 \%) \text { MDD, } 95 \\
(90 \%) \text { for small } \\
\text { firms }\end{array}$ & uniform \\
\hline This study & 1973-2011 & daily & $\begin{array}{l}\text { US, UK, } \\
\text { JAP, } \\
\text { CAN, } \\
\text { AUS }\end{array}$ & $\begin{array}{l}\text { (i) SD, TWSD, } \\
\text { MAD, ES, LPM } \\
\text { (ii) Sharpe, } \\
\text { Sortino, Omega, } \\
\text { skew, kurtosis } \\
\text { (iii) } R^{2}\end{array}$ & $\begin{array}{l}\text { all listed and } \\
\text { delisted stocks on } \\
\text { NYSE, NASDAQ, } \\
\text { LSE, TSE, TSX, } \\
\text { ASX, 37 } \\
\text { subperiods }\end{array}$ & 1000 & $\begin{array}{l}\text { full sample, } \\
\text { equally } \\
\text { weighted }\end{array}$ & 10000 & & uniform \\
\hline
\end{tabular}

Abbreviations: SD - time series standard deviation of portfolio returns, TWSD - portfolio terminal wealth standard deviation, MAD - mean absolute deviation, MDD mean derived dispersion, MRD - mean realized dispersion, NV - normalized variance

Countries: US - United States, UK - United Kingdom, FR - France, DE - Germany, CH - Switzerland, BE - Belgium, NL - Netherlands, IT - Italy, AUS - Australia, CAN - Canada

Exchanges: NYSE - New York Stock Exchange, NASDAQ, LSE - London Stock Exchange, TSE - Tokyo Stock Exchange, TSX - Toronto Stock Exchange, ASX - Australian Stock Exchange. 
(A) United States

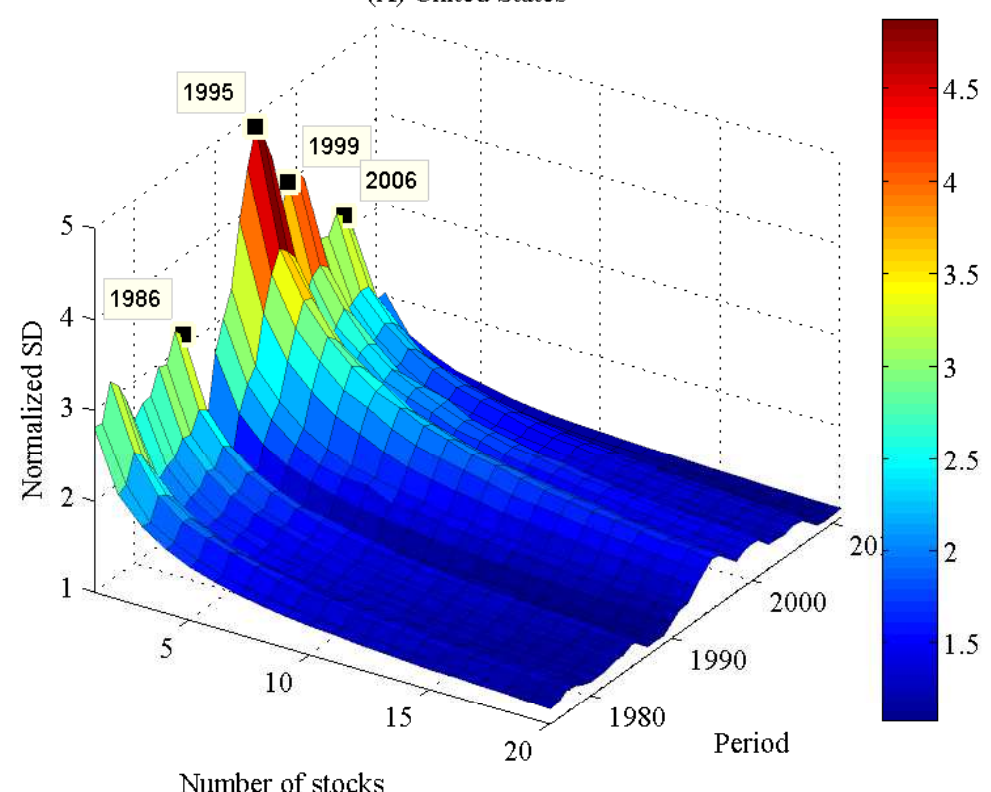

(B) United States

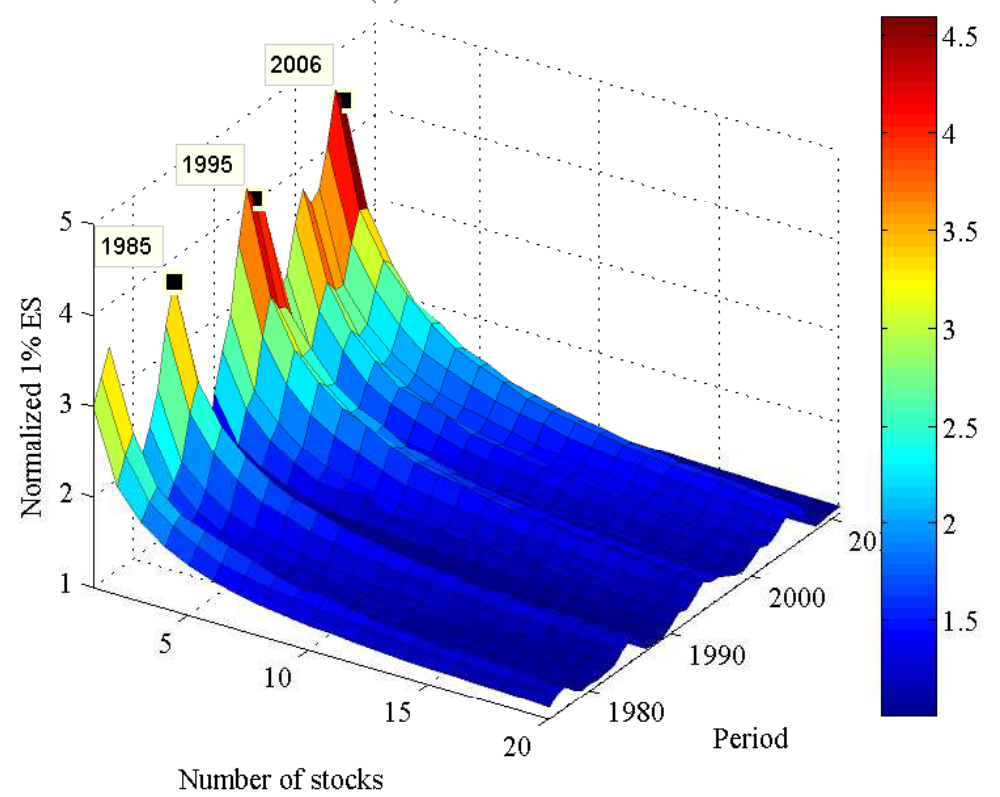

Figure 13: United States. Panel (A) shows the average level of an $n$-stock portfolio standard deviation normalized by the market standard deviation as defined by (??) above. For each year from 1975 to 2011 we construct an asymptote and show the average $n$-stock portfolio standard deviation for $n=1$..20 relative to the market standard deviation for each year (e.g. in 1995 the average security standard deviation was almost five times higher than the market standard deviation). Similarly, Panel (B) shows the average level of $E S_{1 \%}$ for an $n$-stock portfolio normalized by the market $E S_{1 \%}$ (e.g. in 1995 the average security $E S_{1 \%}$ was four times higher than that of the market portfolio). In both panels, when $n \rightarrow N$, the normalized measure approaches 1 . In both cases, slower convergence requires a larger portfolio size to reduce diversifiable risk. 


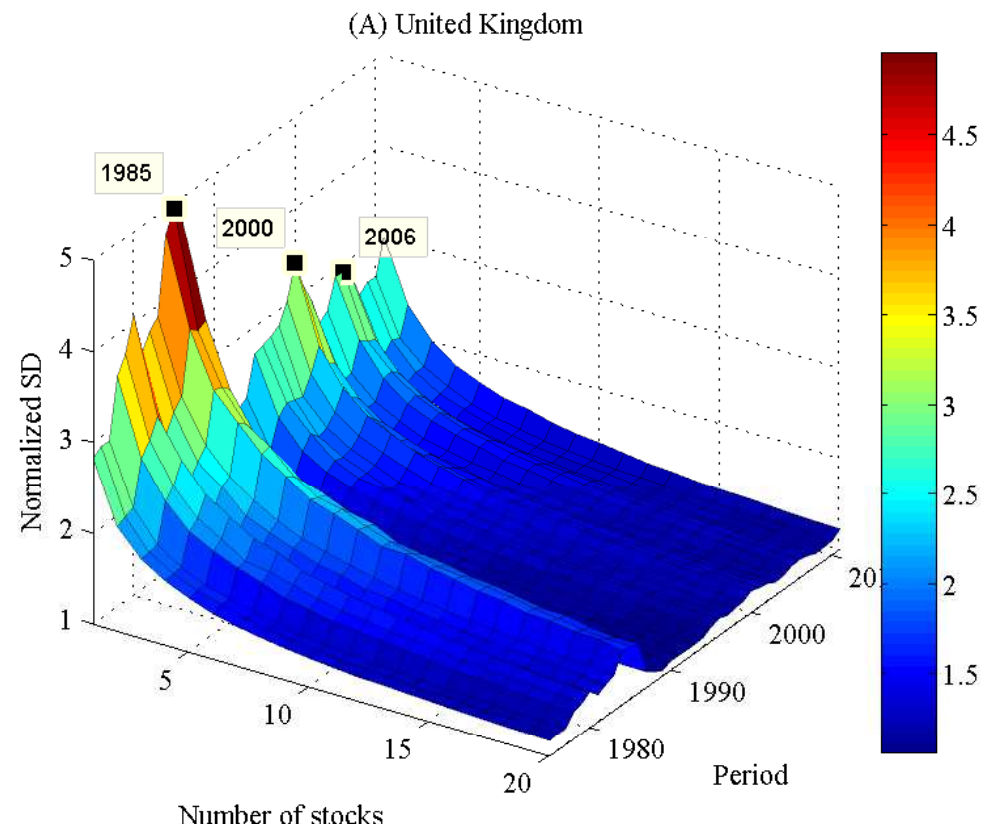

(B) United Kingdom

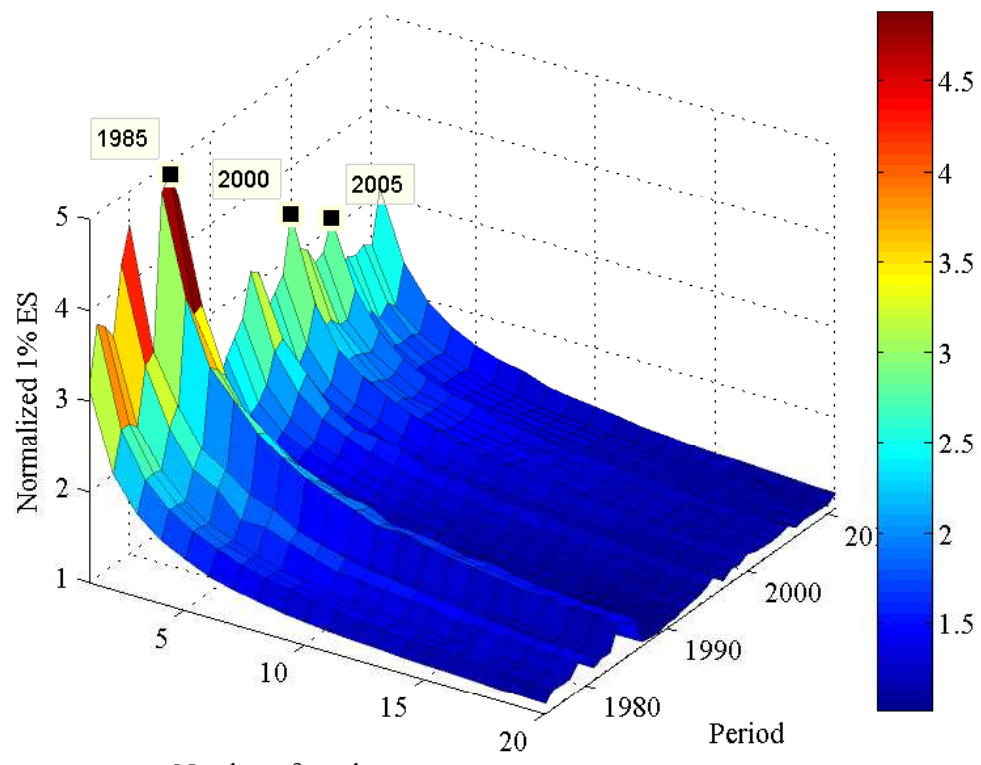

Number of stocks

Figure 14: United Kingdom. Panel (A) shows the average level of an $n$-stock portfolio standard deviation normalized by the market standard deviation as defined by (??) above. For each year from 1975 to 2011 we construct an asymptote and show the average $n$-stock portfolio standard deviation for $n=1 . .20$ relative to the market standard deviation for each year (e.g. in 1985 the average security standard deviation was almost five times higher than the market standard deviation). Similarly, Panel (B) shows the average level of $E S_{1 \%}$ for an $n$-stock portfolio normalized by the market $E S_{1 \%}$ (e.g. in 1985 the average security $E S_{1 \%}$ was five times higher than that of the market portfolio). In both panels, when $n \rightarrow N$, the normalized measure approaches 1 . In both cases, slower convergence requires a larger portfolio size to reduce diversifiable risk. 
(A) Japan

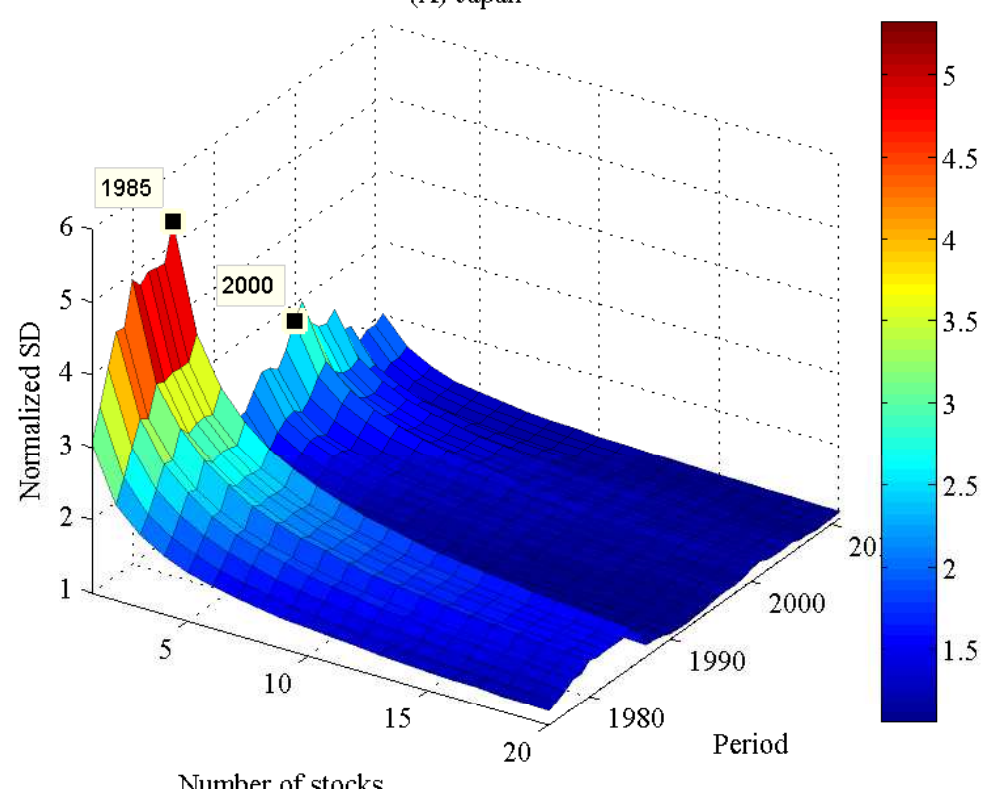

(B) Japan

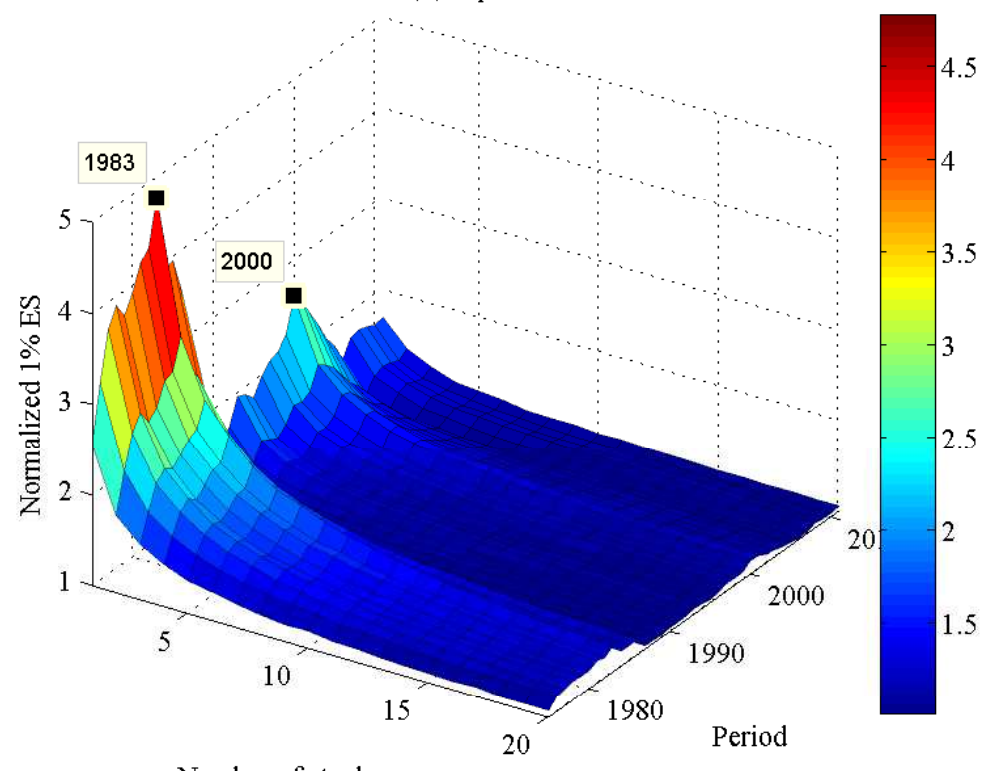

Number of stocks

Figure 15: Japan. Panel (A) shows the average level of an $n$-stock portfolio standard deviation normalized by the market standard deviation as defined by (??) above. For each year from 1975 to 2011 we construct an asymptote and show the average $n$-stock portfolio standard deviation for $n=1 . .20$ relative to the market standard deviation for each year (e.g. in 1985 the average security standard deviation was more than five times higher than the market standard deviation). Similarly, Panel (B) shows the average level of $E S_{1 \%}$ for an $n$-stock portfolio normalized by the market $E S_{1 \%}$ (e.g. in 1983 the average security $E S_{1 \%}$ was five times higher than that of the market portfolio). In both panels, when $n \rightarrow N$, the normalized measure approaches 1. In both cases, slower convergence requires a larger portfolio size to reduce diversifiable risk. 
(A) Canada

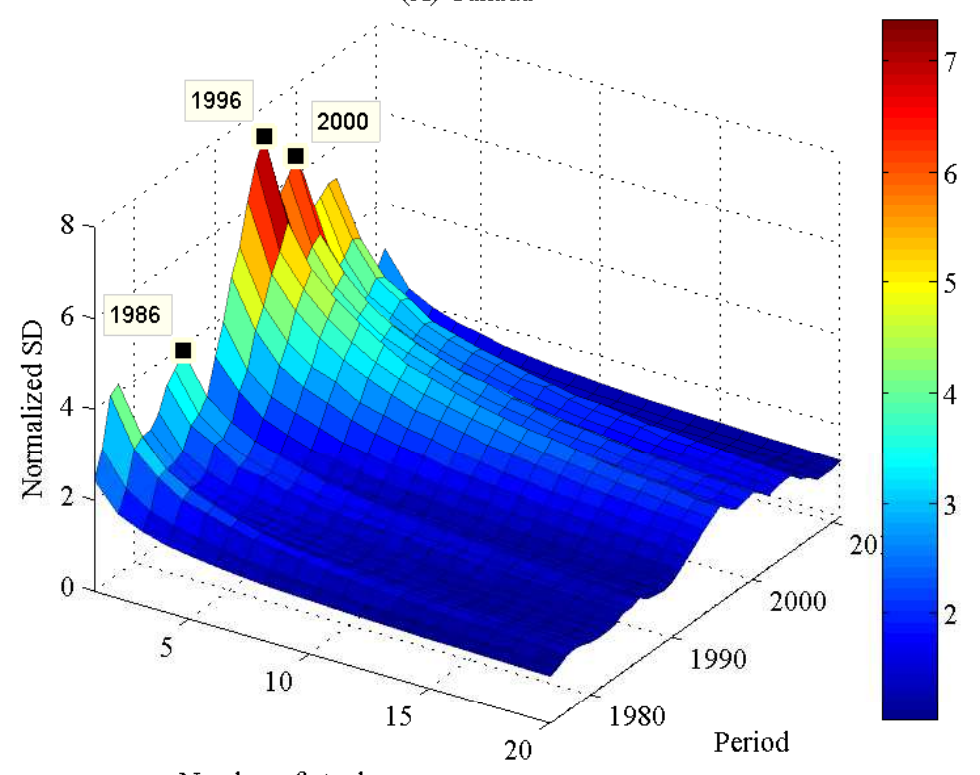

Number of stocks

(B) Canada

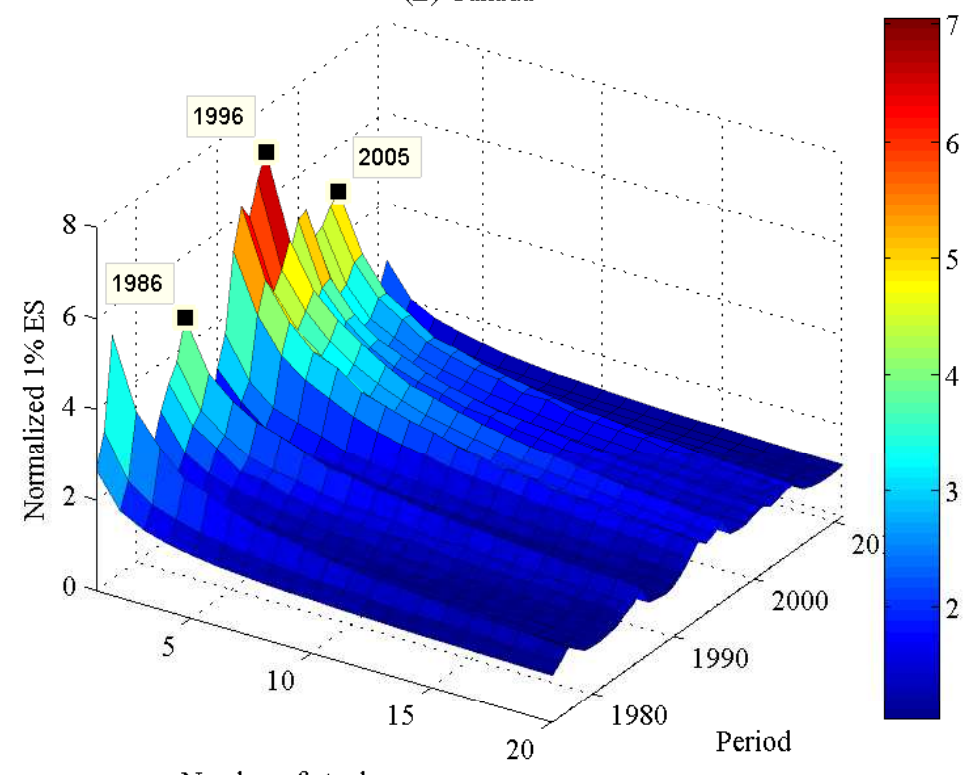

Number of stocks

Figure 16: Canada. Panel (A) shows the average level of an $n$-stock portfolio standard deviation normalized by the market standard deviation as defined by (??) above. For each year from 1975 to 2011 we construct an asymptote and show the average $n$-stock portfolio standard deviation for $n=1 . .20$ relative to the market standard deviation for each year (e.g. in 1996 the average security standard deviation was almost seven times higher than the market standard deviation). Similarly, Panel (B) shows the average level of $E S_{1 \%}$ for an $n$-stock portfolio normalized by the market $E S_{1 \%}$ (e.g. in 1996 the average security $E S_{1 \%}$ was seven times higher than that of the market portfolio). In both panels, when $n \rightarrow N$, the normalized measure approaches 1. In both cases, slower convergence requires a larger portfolio size to reduce diversifiable risk. 
(A) Australia

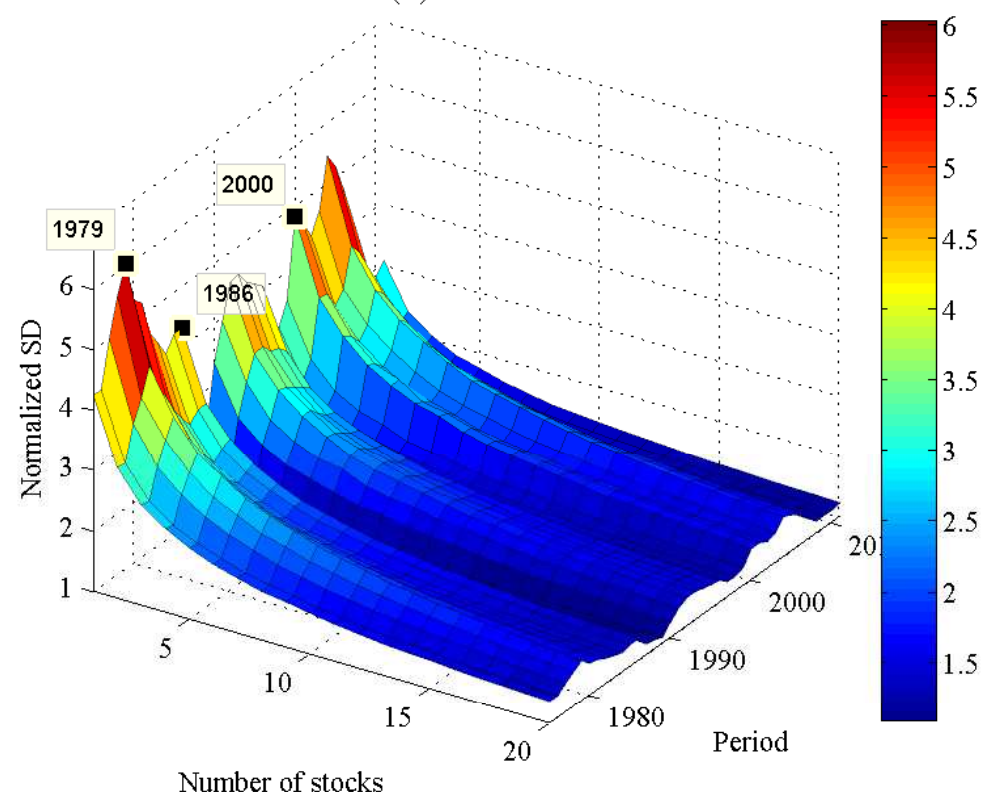

(B) Australia

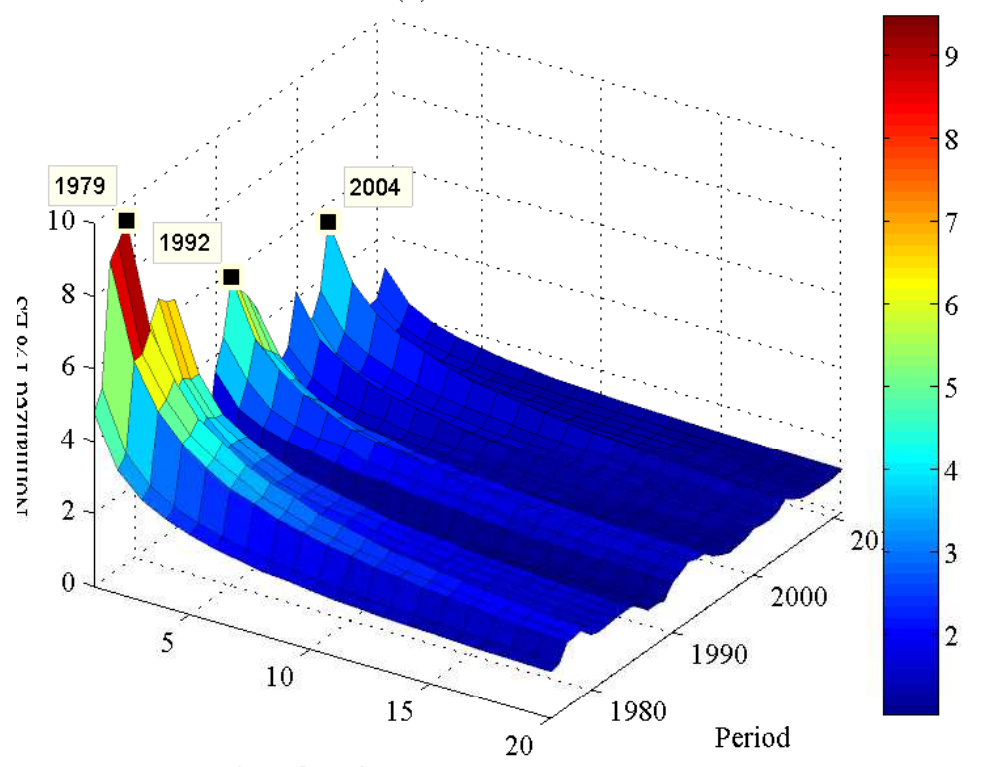

Number of stocks

Figure 17: Australia. Panel (A) shows the average level of an $n$-stock portfolio standard deviation normalized by the market standard deviation as defined by (??) above. For each year from 1975 to 2011 we construct an asymptote and show the average $n$-stock portfolio standard deviation for $n=1 . .20$ relative to the market standard deviation for each year (e.g. in 1979 the average security standard deviation was six times higher than the market standard deviation). Similarly, Panel (B) shows the average level of $E S_{1 \%}$ for an $n$-stock portfolio normalized by the market $E S_{1 \%}$ (e.g. in 1979 the average security $E S_{1 \%}$ was nine times higher than that of the market portfolio). In both panels, when $n \rightarrow N$, the normalized measure approaches 1. In both cases, slower convergence requires a larger portfolio size to reduce diversifiable risk. 

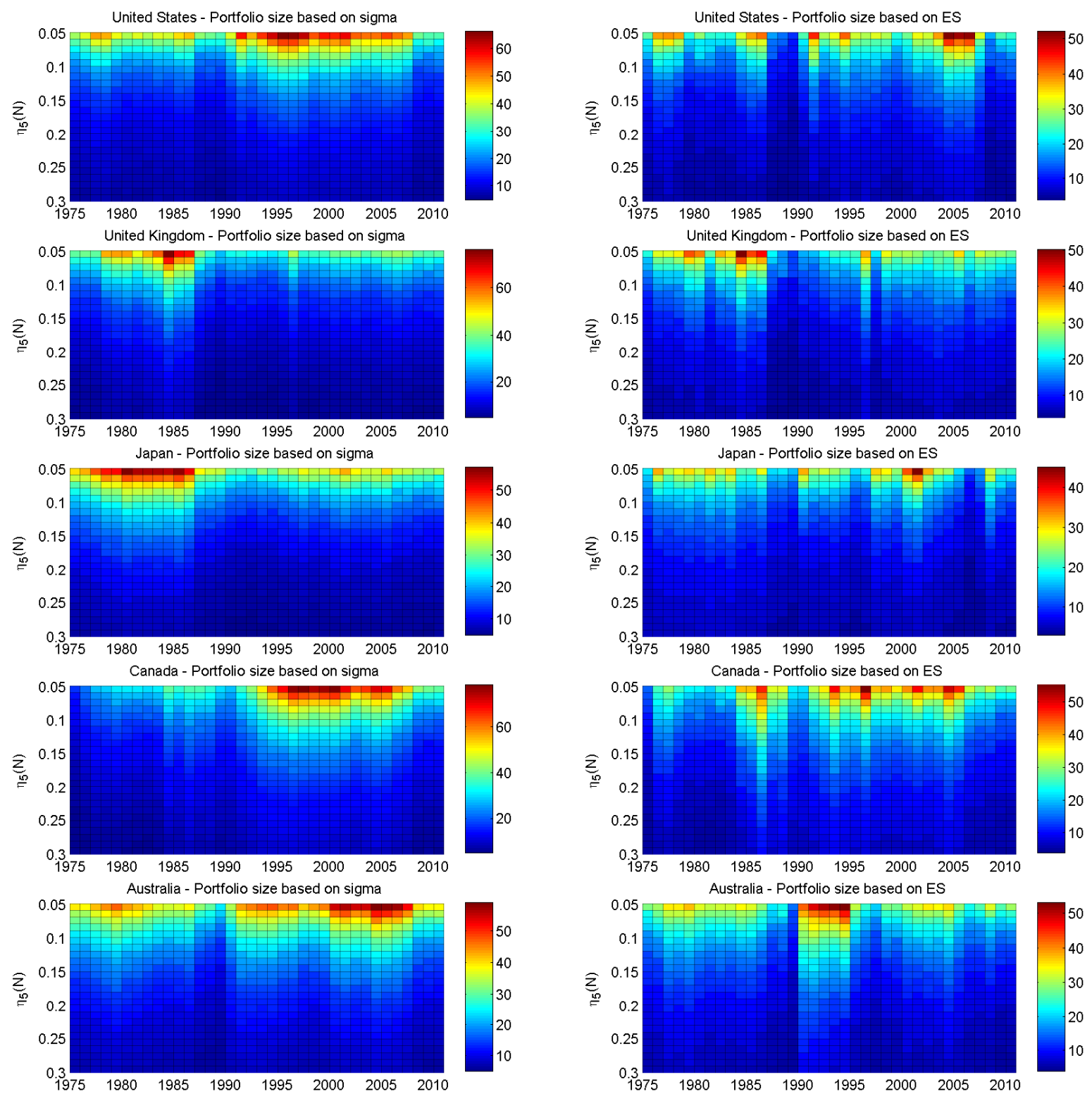

Figure 18: Portfolio size (color bar) by the level of diversification (vertical axis) across time (horizontal axis). Based on our collected historical data we estimate the number of stocks an investor should have held on average (higher number of stocks are represented in red, small number of stocks are in blue) to achieve a desired level of diversification ( $x$-axis) throughout the last 37 years. Left panels represent our recommendations based on variance as a measure of risk. Right panels outline recommendations based on $1 \%$ Expected Shortfall (ES) if taken as a measure of risk. For all the countries and across most years the number of stocks required to reduce the level of the risk measure concerned is lower if the investor is concerned with reduction of extreme losses. When $\eta_{5}(n)$ is equal to 0.05 or 0.1 , for example, the level of diversification is equivalent to $95 \%$ or $90 \%$ reduction in diversifiable risk respectively. 


\section{School of Economics and Finance Discussion Papers}

2013-20 Towards a Diagnostic Approach to Climate Adaptation for Fisheries, P. Leith, E. Ogier, G. Pecl, E. Hoshino, J. Davidson, M. Haward

2013-19 Equity Portfolio Diversification with High Frequency Data, Vitali Alexeev and Mardi Dungey

2013-18 Measuring the Performance of Hedge Funds Using Two-Stage Peer Group Benchmarks, Marco Wilkens, Juan Yao, Nagaratnam Jeyasreedharan and Patrick Oehler

2013-17 What Australian Investors Need to Know to Diversify their Portfolios, Vitali Alexeev and Francis Tapon

2013-16 Equity Portfolio Diversification: How Many Stocks are Enough? Evidence from Five Developed Markets, Vitali Alexeev and Francis Tapon

2013-15 Equity market Contagion during the Global Financial Crisis: Evidence from the World’s Eight Largest Economies, Mardi Dungey and Dinesh Gajurel

2013-14 A Survey of Research into Broker Identity and Limit Order Book, Thu Phuong Pham and P Joakim Westerholm

2013-13 Broker ID Transparency and Price Impact of Trades: Evidence from the Korean Exchange, Thu Phuong Pham

2013-12 An International Trend in Market Design: Endogenous Effects of Limit Order Book Transparency on Volatility, Spreads, depth and Volume, Thu Phuong Pham and P Joakim Westerholm

2013-11 On the Impact of the Global Financial Crisis on the Euro Area, Xiaoli He, Jan PAM Jacobs, Gerald H Kuper and Jenny E Ligthart

2013-10 International Transmissions to Australia: The Roles of the US and Euro Area, Mardi Dungey, Denise Osborn and Mala Raghavan

2013-09 Are Per Capita $\mathrm{CO}_{2}$ Emissions Increasing Among OECD Countries? A Test of Trends and Breaks, Satoshi Yamazaki, Jing Tian and Firmin Doko Tchatoka

2013-08 Commodity Prices and BRIC and G3 Liquidity: A SFAVEC Approach, Ronald A Ratti and Joaquin L Vespignani

2013-07 Chinese Resource Demand and the Natural Resource Supplier Mardi Dungy, Renée Fry-McKibbin and Verity Linehan

2013-06 Not All International Monetary Shocks are Alike for the Japanese Economy, Joaquin L Vespignani and Ronald A Ratti

2013-05 On Bootstrap Validity for Specification Tests with Weak Instruments, Firmin Doko Tchatoka

2013-04 Chinese Monetary Expansion and the US Economy, Joaquin L Vespignani and Ronald A Ratti

2013-03 International Monetary Transmission to the Euro Area: Evidence from the US, Japan and China, Joaquin L Vespignani and Ronald A Ratti

2013-02 The impact of jumps and thin trading on realized hedge ratios? Mardi Dungey, Olan T. Henry, Lyudmyla Hvozdyk

2013-01 Why crude oil prices are high when global activity is weak?, Ronald A Rattia and Joaquin L Vespignani

Copies of the above mentioned papers and a list of previous years' papers are available from our home site at http://www.utas.edu.au/economics-finance/research/ 